九州大学学術情報リポジトリ

Kyushu University Institutional Repository

Analyses of diagnostic failure effect and failsafe ignited operation in a tokamak fusion reactor

Mitarai, Osamu

Kyushu Tokai University, Department of Electrical Engineering

Muraoka, Katsunori

Kyushu University, Interdisc. Grad. Sch. of Eng. Sci., Department of Energy Conversion

http://hdl. handle. net/2324/784720

出版情報：Fusion Technol. 36 (2)，pp.194-211，1999-01-01. ANS バージョン :

権利関係 : 


\title{
ANALYSES OF DIAGNOSTIC FAILURE EFFECT AND FAIL-SAFE IGNITED OPERATION IN A TOKAMAK FUSION REACTOR
}

\author{
OSAMU MITARAI* Kyushu Tokai University \\ Department of Electrical Engineering, 9-1-1 Toroku \\ Kumamoto 862-8652, Japan
}

\author{
KATSUNORI MURAOKA Kyushu University \\ Interdisciplinary Graduate School of Engineering Sciences \\ Department of Energy Conversion, 6-1 Kasuga Koen, Kasuga \\ Fukuoka 816-8580, Japan
}

Received May 24, 1998

Accepted for Publication January 15, 1999

The consequence of the failure effect of burn control diagnostic systems, such as neutron diagnostics, bolometers, electron cyclotron emission power loss diagnostics, interferometer, and lost alpha detector, on ignited operation has been analyzed, and the fail-safe operation in a tokamak fusion reactor including the International Thermonuclear Experimental Reactor (ITER) has been considered. Because the failure of the neutron diagnostic system for fusion power measurement leads to a fusion power surge for the simple control algorithm, the fail-safe control algorithm has been introduced to avoid this problem. As failure of the power loss measurement such as the bolometer system terminates the ignition, then it is less problematic. The effect of the interferometer fringe counting error on the ignited operation is not simple, as just mentioned, and a lost alpha detector can be removed from the feedback system using the preset value.

\section{INTRODUCTION}

Although the safety issues on the loss-of-coolant accident (LOCA) in the ex-vessel components ${ }^{1}$ and invessel LOCA initiated by the loss of plasma control, ${ }^{2,3}$ the magnet failure, ${ }^{4}$ and the other failure scenarios ${ }^{5-9}$ have been analyzed for the International Thermonuclear Experimental Reactor (ITER), the safety aspect caused by

*E-mail: omitarai@ktmail.ktokai-u.ac.jp

the diagnostic failure effect on the ignited operation has not been considered so far despite the active development of various diagnostic system and ignition analyses in a tokamak reactor. ${ }^{10-17}$ Therefore, the TAC-12 report has recently recommended that the fail-safe operation in ITER related to the diagnostic system should be considered and analyzed. ${ }^{18}$ This type of analysis on failure modes and effects analyses of each diagnostic system is also necessary for developing a fusion reactor. Recently, burn control diagnostic systems have been proposed based on examination of various control algorithms by authors for a fusion reactor, including ITER, ${ }^{19,20}$ which is developed independently of the ITER team. ${ }^{21-26}$ Based on this work, it is possible to see how the ignited operation behaves after the diagnostic failure. To meet the part of the TAC-12 request and consider the diagnostic failure effect on ignition in a future reactor, we tackle these issues using the method developed for ignition burn control.

We recognize that the following diagnostic failure scenarios exist in a reactor including ITER. Such possibility of the events can be classified as the failure of the (a) diagnostic system, (b) controller systems, and (c) actuator systems. These all are involved in the diagnostic/ control systems. We have defined the failure in the diagnostic and control systems as the loss-of-signal event (LOSE) in this paper, named similarly to the loss-ofcoolant accident (LOCA), the loss-of-flow accident (LOFA), the loss-of-vacuum event (LOVA), and the ingress of coolant event (ICE), etc., although the accident level and features may be different with respect to radioactive release.

LOSE of a diagnostic system in a fusion reactor may be categorized as follows: 
1. Failure of various burn control diagnostic systems: As this may lead to some serious operation or ignition termination if no backup systems exist, we examine the consequence of the failure of the several diagnostic systems such as neutron measurements, bolometers, and interferometer involved in the feedback burn control algorithm. A fail-safe algorithm has also been considered to avoid this problem.

2. Failure of the magnetic control diagnostics: The failure of magnetic probes for the plasma position measurements may lead to the plasma disruption. Therefore, a microwave reflectometer system has to be used for a backup for the magnetic probe signals for the horizontal movement. On the other hand, the soft X-ray array detectors may be used for a backup system for the magnetic probe signals for the vertical movement. ${ }^{21}$ Magnetic probe failure itself may be caused by the coolant leak, mechanical vibration, neutron irradiation, and LOSE of the magnetic probes by a failure in the cable, data processing, and controller. As we assume the backup system, we do not treat this problem here.

3. Power failure of the machine during burn operation: This also leads to LOSE and disruption. Therefore, "killer" or "safety shutdown" pellet injection should be operated when the power failure takes place during the fusion burn operation.

Even when the unknown diagnostic failure and abnormal events take place, the fast plasma shutdown method can be finally used independently of the control system. Although disruption is thought to be a part of unavoidable normal operational transient phenomena from the experimental point of view and not an "accident," the slow fusion burn termination is attempted to be achieved to minimize or avoid disruption for extending the lifetime of the divertor plate in a future fusion reactor in this study.

After the control concept integrated with the magnetic control, magnetohydrodynamic (MHD) control, burn control, and divertor control are extensively studied, their diagnostic failure effects should be discussed on this basis. However, as ignition burn control (which is called a kinetic control by the ITER team, as compared to the MHD control) is essentially independent of the magnetic control, such as the plasma current, plasma position, and plasma shape, a burn control algorithm can be discussed separately from these controls. ${ }^{26}$ On this basis, the plasma core burn control algorithm was proposed using the external heating power from the H-mode power threshold to keep the H-mode and fueling to keep the fusion power at the desired value. ${ }^{19,20}$ This control algorithm to keep such quantities has been confirmed to work well for the case of a sudden change in the plasma parameters, such as a sudden change in the confinement factor, alpha ash confinement time, sudden injection of impurities and ab- sorbed fuels, sudden increase in the alpha-particle loss, etc. ${ }^{16}$ We should note that as for the sudden change in the plasma position, although this feedback control has not been tested yet, the same feedback control algorithm for an ignition burn is expected to manage this situation. This is because the change in the plasma position affects the confinement time through the change in the major radius in the confinement scaling or affects the alpha ash due to compression or expansion of the plasma volume. ${ }^{13}$ Only this case gives a connection between the magnetic control and burn control. Therefore, it is timely to consider the diagnostic failure effect on ignition using this control algorithm, decoupled from a magnetic control.

Analyses of the loss of plasma control were done from the machine safety point of view by the ITER team., ${ }^{2,3,27}$ The following four transient cases were examined for the cases of increase in fueling, fueling stop, sudden doubling of confinement time, and sudden injection of 100-MW heating power into an ignited plasma. ${ }^{27}$ In this study, the plasma transient behaviors initiated by artificial parameter change to simulate the loss of plasma control and plasma anomaly are studied to check whether the fusion power can be safely terminated and to assess the potential damage to the machine in detail without taking a safety credit of the burn control system. Therefore, analyses of the loss of plasma control may envelop a part of the studies of the diagnostic failure effects, but there is no discussion about which diagnostic failure and how it affects the ignited operation from an actual operating point of view with a feedback burn control algorithm. ${ }^{2,27}$

In this paper, we first show the consequence of the ignited operation caused by the loss of signal event in the burn control diagnostic systems and propose the fail-safe control algorithm against the diagnostic failure to prevent anomalous behavior in ignited operations. This study is based on the most plausible feedback control algorithm in a future tokamak reactor, including ITER, obtained from the present knowledge of the $\mathrm{H}$-mode power threshold, although it is still uncertain whether the $\mathrm{H}$-mode power threshold is a good navigator to ignition or not. In this study of the diagnostic failure effect on ignited operation, an attempt was made for the disruptive termination of the ignited operation to be minimized or avoided to extend the lifetime of the divertor plate. The ultimate aim of this study is therefore to find a control concept consisting of a diagnostic network, which can check the performance degradation of the diagnostics and detect the abnormal signal or LOSE and hence is robust to the diagnostic failures, in order to enhance the reliability of the tokamak reactor operation. As the diagnostic failure is equivalent to an "open loop" of the feedback control system, the fail-safe control algorithm can be employed as proposed here using parallel feedback loops with many diagnostics so as not to open the feedback loop.

This paper is organized as follows. In Sec. II, the feedback control algorithms with measuring errors for ignited operations are presented. In Sec. III, the LOSE 
effect of the neutron diagnostic system is presented on ignited operation. A fail-safe operation is described. In Sec. IV, the LOSE effect of the bolometer system is discussed. In Sec. V, the fringe counting error effects in the interferometer on an ignited operation are analyzed. In Sec. VI, the method to remove the lost alpha detector is examined and proposed. In Secs. VII and VIII, discussion and summary are given, respectively.

\section{FEEDBACK CONTROL ALGORITHM WITH MEASURING ERRORS IN IGNITED OPERATIONS}

Fusion burn control can be done by a feedback control algorithm on the heating power and fueling. We have used the same control algorithm ${ }^{19,20}$ for analyzing diagnostic failure effects on ignition burn in the whole discharge phase, such as the fusion burn rise-up, steady state, and shutdown phases.

\section{II.A. Control Law of the External Heating Power with Measuring Errors Based on the H-Mode Power Threshold}

The external heating power is controlled by the $\mathrm{H}$-mode power threshold given by Takizuka et al. ${ }^{28}$ to keep the H-mode. The following relation has been used for judging the $\mathrm{H}$-L transition. The plasma itself changes the $\mathrm{H}$ and $\mathrm{L}$ modes according to the value of $M_{\mathrm{HL}}$ (actual), such as $\mathrm{H}$ mode for $M_{\mathrm{HL}}$ (actual) $>1$ and $\mathrm{L}$ mode for $M_{\mathrm{HL}}($ actual $)<1$ :

$$
M_{\mathrm{HL}}(\text { actual })=\frac{\bar{P}_{h, n e t}[\mathrm{~W}] V_{o}\left[\mathrm{~m}^{3}\right] \times 10^{-6}}{0.45 \bar{n}^{0.75}\left[10^{20} \mathrm{~m}^{-3}\right] B_{t}[\mathrm{~T}] R^{2}[\mathrm{~m}]},
$$

where

$$
\begin{aligned}
\bar{P}_{h . n e t}= & \text { net heating power density given by } \bar{P}_{h, \text { net }}= \\
& P_{E X T}(\mathrm{HL}) / V_{o}+\bar{P}_{o h}+\bar{P}_{\alpha}-\left\{\bar{P}_{b}+\bar{P}_{s}\right\} \\
\bar{n}= & \text { line-averaged density } \\
B_{t}= & \text { toroidal field } \\
R= & \text { major radius } \\
\bar{P}_{o h}= & \text { ohmic heating power } \\
\bar{P}_{\alpha}= & \text { alpha-heating power density } \\
\bar{P}_{b}= & \text { bremsstrahlung loss per unit volume } \\
\bar{P}_{s}= & \text { synchrotron radiation loss per unit volume } \\
V_{o}= & \text { plasma volume. }
\end{aligned}
$$

Therefore, the foregoing formula provides the external heating power for the feedback control to keep the H-mode. ${ }^{17,18}$

When the measuring error is taken into account, such as the measuring error in the neutron measurement $\epsilon_{p n}$, the measuring error in the density measurement $\epsilon_{n}$, the measuring error in the bremsstrahlung power loss $\epsilon_{b}$, and the measuring error in the synchrotron radiation power loss $\epsilon_{s}$, the external heating power is given by

$$
\begin{aligned}
P_{E X T}(\mathrm{HL})[\mathrm{W}]= & M_{\mathrm{HL} 0} 0.45 \times 10^{6}\left\{\bar{n}\left(1+\epsilon_{n}\right)\right\}^{0.75} \\
\times & {\left[10^{20} \mathrm{~m}^{-3}\right] B_{t}[\mathrm{~T}] R^{2}[\mathrm{~m}] } \\
- & \left\{\bar{P}_{o h}+\bar{P}_{\alpha}\left(1+\epsilon_{p n}\right)-\bar{P}_{b}\left(1+\epsilon_{b}\right)\right. \\
& \left.-\bar{P}_{s}\left(1+\epsilon_{s}\right)\right\} V_{o},
\end{aligned}
$$

where $M_{\mathrm{HL} 0}$ is the set value of the H-mode indicator of 1.05 in this study.

In general, the complete LOSE in a diagnostic system corresponds to $\epsilon_{i}=-1$ (where $i=n, p n, b$, and $s$ ) in this definition, and the loss of half the signals (equivalent to the loss of $50 \%$ of the channels of the multichannel diagnostics) corresponds to $\epsilon_{i}=-0.5$. Therefore, the level of the abnormal behavior in diagnostic systems can be expressed by the range of $-1 \leq \epsilon_{i} \leq+1$. Using this expression, we can also analyze the measurement error effects on the ignited operation, where for instance $\epsilon_{i}=$ +0.1 means a $10 \%$ overestimation error and $\epsilon_{i}=-0.1$ means a $10 \%$ underestimation error.

\section{II.B. Control Law of Fueling with Measuring Errors}

The fueling rate is controlled by the measured fusion power signal of $P_{f s i g}=P_{f}\left(1+\epsilon_{p n}\right)$ as follows:

$$
S_{\mathrm{DT}}(t)=S_{\mathrm{DT} 0}\left(1-\frac{P_{f}\left(1+\epsilon_{p n}\right)}{P_{f o}(t)}\right) G_{f o}(t),
$$

where $S_{\mathrm{DT} 0}=1 \times 10^{19} \mathrm{~m}^{-3} / \mathrm{s}$ and $G_{f o}$ is the timedependent gain as given later. The total fusion power is defined by the neutron power plus the birth alphaheating power $P_{f}=\left(\bar{P}_{\underline{n}}+\bar{P}_{\alpha} / \eta_{\alpha}\right) V_{o}$. We should note here that the notation $\bar{P}_{\alpha} / \eta_{\alpha}$ is the birth alpha-heating power before alpha loss as defined in the Appendix.

The target control value for the total fusion power in the fusion power rise-up phase is given by

$$
P_{f o}(t)=P_{f s}+\frac{P_{f e}-P_{f s}}{t_{f e}-t_{f s}}\left(t-t_{f s}\right),
$$

where the following parameters have been chosen as $t_{f s}=5 \mathrm{~s}, t_{f e}=55 \mathrm{~s}, \tau_{\text {rise }}=t_{f e}-t_{f s}=50 \mathrm{~s}, P_{f e}=1.5 \mathrm{GW}$, and $P_{f s}=100 \mathrm{MW}$ for the fusion power rise-up phase of $t_{f s}<t<t_{f e}$. The value $P_{f o}=P_{f e}=1.5 \mathrm{GW}$ is given for the fusion power flat phase of $t_{f e}<t$. In the fusion burn shutdown phase, a linearly decreasing function is assumed using the same Eq. (4), with $t_{f s}=1000$, 
$t_{f e}=1000+\tau_{d o w n}, \tau_{d o w n}=40 \mathrm{~s}, P_{f s}=1.5 \mathrm{GW}$, and $P_{f e}=$ $50 \mathrm{MW}$.

To avoid unstable operation during the rise-up phase, the time variable gain was employed in this paper as follows:

$$
G_{f o}(t)=G_{f s}+\frac{G_{f e}-G_{f s}}{t_{f e}-t_{f s}}\left(t-t_{f b s}\right),
$$

where the feedback starting time is $t_{f b s}=12 \mathrm{~s}$, the final gain is $G_{f e}=50$ at $t_{f e}$ and the initial gain is $G_{f s}=5$ at $t_{f s}$.

\section{II.C. Combined Control Algorithm}

We first consider the simplest fusion burn control using the heating power $P_{E X T}(\mathrm{HL})$ based on the $\mathrm{H}$-mode power threshold and fueling $S_{\mathrm{DT}}\left(P_{f}\right)$ on the fusion power. We describe this algorithm as a set of $\left\{P_{E X T}(\mathrm{HL})\right.$ and $\left.S_{\mathrm{DT}}\left(P_{f}\right)\right\}$, where a set of diagnostics to fulfill this control algorithm is also involved. Secondly, we consider the failsafe operation where fueling is controlled by multiple parameters. We call this a combined or fail-safe control algorithm by a set of $\left\{P_{E X T}(\mathrm{HL})\right.$ and $\min \left\{S_{\mathrm{DT}}\left(P_{f}\right), S_{\mathrm{DT}}(n)\right.$, $\left.\left.S_{\mathrm{DT}}(\langle\beta\rangle)\right\}\right\}$. Here, only the diamagnetic loop measurement is added for this control algorithm.

\section{II.C.1. Simple Control Algorithm by a Set of $\left\{P_{E X T}(\mathrm{HL})\right.$ and $\left.S_{\mathrm{DT}}\left(P_{f}\right)\right\}$ for all the Phases}

This is a basic control algorithm for fusion burn in a reactor including ITER. As the heating power is controlled by the H-mode power threshold to keep the $\mathrm{H}$ mode and the fueling rate is controlled by the fusion power to keep the fusion power at the desired value, a set of the diagnostic system should work properly during all the burn phases. The diagram for this control algorithm is shown in Fig. 1a, with the neutron source diagnostics such as the microfission chambers to measure the neutron power $P_{n}$, alpha-heating power $P_{\alpha}$, and hence fusion power $P_{f}$, and the lost alpha detector to measure the alpha loss fraction to the first wall $\left(1-\eta_{\alpha}\right)$, bolometers to measure the bremsstrahlung power loss $P_{b}$, the electron cyclotron emission detector to measure the power loss $P_{s}$, and the interferometer to measure line-averaged density $\bar{n}$. As the ohmic heating power by the plasma current $I_{p}$ and the loop voltage $V_{\ell}$ is small, then the failure effect of these measurements is neglected in this study. As seen in this figure, failure in the neutron diagnostic system affects the feedback control of both the heating power and fueling.
II.C.2. Fail-Safe Control Algorithm by $\left\{P_{E X T}(\mathrm{HL})\right.$ and $\left.\min \left\{S_{\mathrm{DT}}\left(P_{f}\right), S_{\mathrm{DT}}(n(0)), S_{\mathrm{DT}}(\langle\beta\rangle)\right\}\right\}$

The control algorithm worked within the performance limitation, such as the Greenwald density limit ${ }^{29}$ or the beta limit, and has a fail-safe function in ignited operation when the diagnostic failure takes place. The heating power is controlled by the H-mode power threshold, and fueling is controlled either by the fusion power, density, or beta value as given by a set of $\left\{P_{E X T}(\mathrm{HL})\right.$ and $\left.\min \left\{S_{\mathrm{DT}}\left(P_{f}\right), S_{\mathrm{DT}}(n), S_{\mathrm{DT}}(\langle\beta\rangle)\right\}\right\}$, where

$$
S_{\mathrm{DT}}(n)=S_{\mathrm{DT} 0}\left(1-\frac{n(0)\left(1+\epsilon_{n}\right)}{n(0)_{G W}}\right) G_{f o}
$$

and

$$
S_{\mathrm{DT}}(\langle\beta\rangle)=S_{\mathrm{DT} 0}\left(1-\frac{\langle\beta\rangle\left(1+\epsilon_{\beta}\right)}{\langle\beta\rangle_{\max }}\right) G_{f o},
$$

where

$$
\begin{aligned}
n(0)_{G W} & =\text { Greenwald density limit } \\
\langle\beta\rangle_{\max } & =\text { maximum beta value } \\
\epsilon_{\beta} & =\text { measuring error in the beta measurement. }
\end{aligned}
$$

When the Greenwald density limit $n(0)_{G W}$ is set at a relatively lower value than the operation density and the maximum beta value is set at a larger value, then the fusion power is regulated by the density feedback control. On the other hand, when the Greenwald density limit $n(0)_{G W}$ is set at a higher value than the operation density and the maximum beta value is set at a lower value, the fusion power is regulated by the beta value feedback control. The control diagram for this case is shown in Fig. 1b. As fueling is controlled by three diagnostics in parallel, the other diagnostic system can help when one diagnostic system has a failure. In this study, the beta value is measured by the diamagnetic loop, ${ }^{30}$ which is assumed to have no failure $\epsilon_{\beta}=0$.

\section{II.D. Actual and Measured H-Mode Indicators}

We distinguish the two kinds of H-mode indicators as "actual" and "measured." The first one is the actual $\mathrm{H}$-mode indicator given by Eq. (1). The plasma itself changes the $\mathrm{H}$ and $\mathrm{L}$ mode according to the value of $M_{\mathrm{HL}}$ (actual). Therefore, this quantity has been used for judging the $\mathrm{H}-\mathrm{L}$ transition in the following analyses.

Secondly, when the measurement error is taken into account, the measured $\mathrm{H}$-mode indicator is given by

$$
M_{\mathrm{HL}}(\text { meas })=\frac{\left[\frac{P_{E X T}}{V_{o}}+\bar{P}_{o h}+\bar{P}_{\alpha}\left(1+\epsilon_{p n}\right)-\left\{\bar{P}_{b}\left(1+\epsilon_{b}\right)+\bar{P}_{s}\left(1+\epsilon_{s}\right)\right\}\right][\mathrm{W}] V_{0}\left[\mathrm{~m}^{3}\right] \times 10^{-6}}{0.45\left\{\bar{n}\left(1+\epsilon_{n}\right)\right\}^{0.75}\left[10^{20} \mathrm{~m}^{-3}\right] B_{t}[\mathrm{~T}] R^{2}[\mathrm{~m}]} .
$$

However, this judgment is not used in a real situation. 


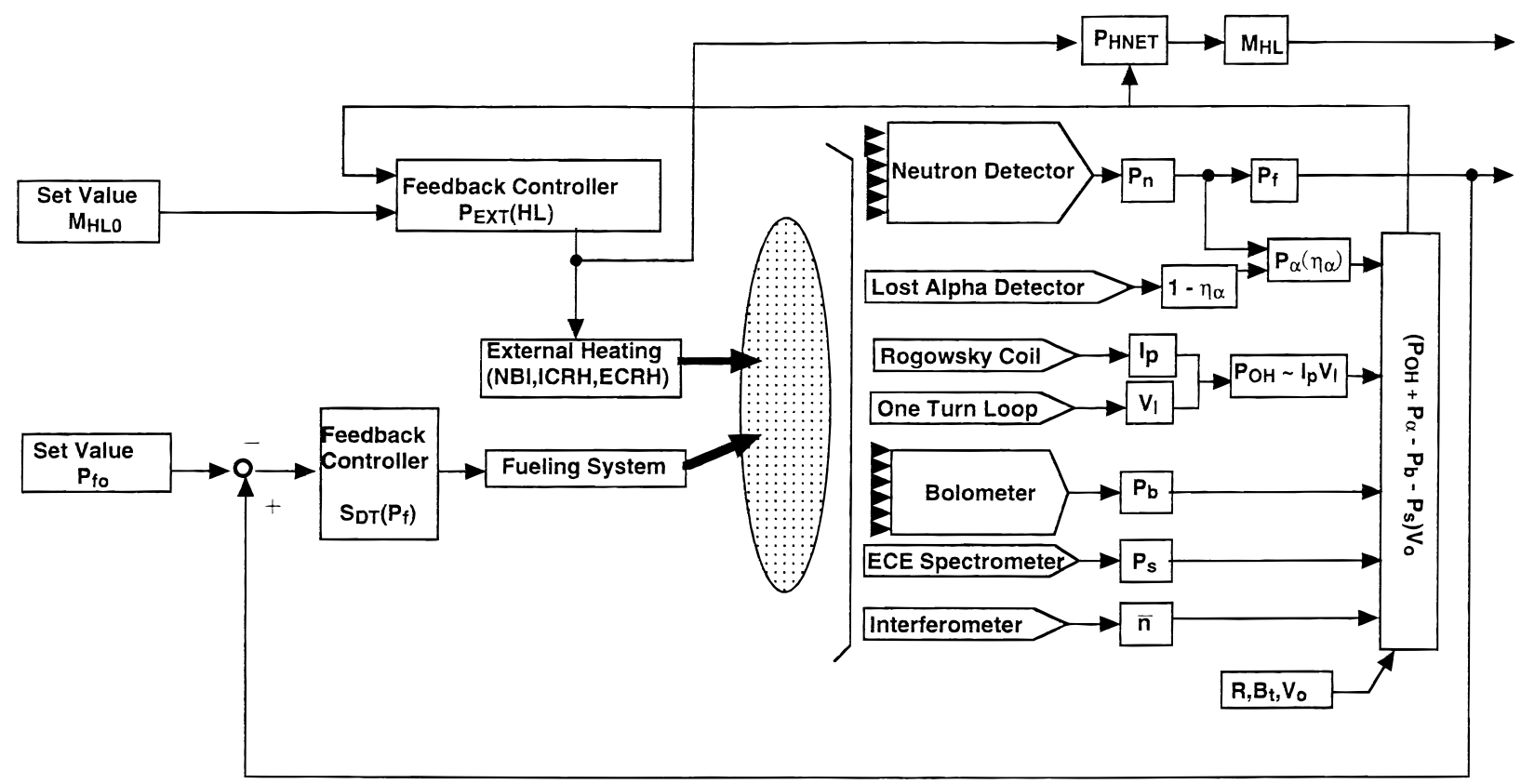

(a)

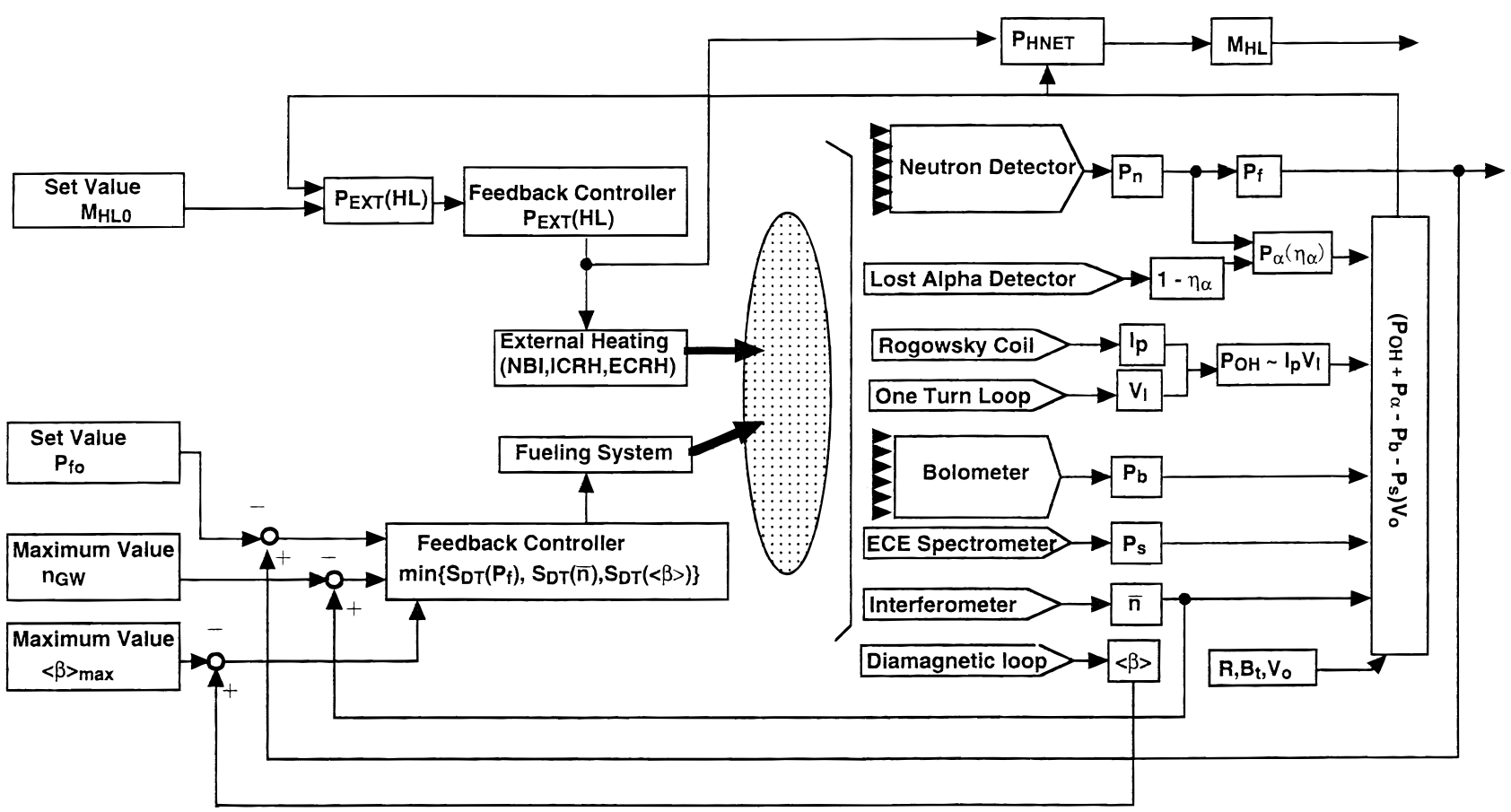

(b)

Fig. 1. The schematic diagram of the feedback system for core ignition burn control in ITER: (a) simple control algorithm of $\left\{P_{E X T}(\mathrm{HL})\right.$, and $\left.S_{\mathrm{DT}}\left(P_{f}\right)\right\}$ and (b) fail-safe control algorithm of $\left\{P_{E X T}(\mathrm{HL})\right\}$ and $\left.\min \left\{S_{\mathrm{DT}}\left(P_{f}\right), S_{\mathrm{DT}}(n), S_{\mathrm{DT}}(\langle\beta\rangle)\right\}\right\}$.

\section{LOSE IN FUSION NEUTRON MEASUREMENTS}

The LOSE in the neutron diagnostic systems would produce severe problems in ignited operation because the feedback signal of fueling becomes maxi- mum as $S_{\mathrm{DT}}=S_{\mathrm{DT} 0} G_{f o}$ due to the null signal $P_{f s i g}=$ $P_{f}\left(1+\epsilon_{p n}\right)=0$ in the proportional feedback control in Eq. (3), and the heating power $P_{E X T}(\mathrm{HL})$ is increased over $100 \mathrm{MW}$ due to $P_{\alpha s i g}=P_{\alpha}\left(1+\epsilon_{p n}\right)=0$ in Eq. (2). 


\section{III.A. Complete LOSE Effects in Neutron Measurements for the Control Algorithm of $\left\{P_{E X T}(\mathrm{HL})\right.$ and $\left.S_{\mathrm{DT}}\left(P_{f}\right)\right\}$}

If a complete $\operatorname{LOSE}\left(\epsilon_{p n}=-1.0\right)$ in neutron diagnostics takes place in any phase of the fusion burn phase, the fusion power immediately increases by sudden increase in the fueling and heating power. As shown in Fig. 2, when the measured fusion power signal $P_{f s i g}$ for the feedback control is suddenly lost to zero at $t=60 \mathrm{~s}$ during the steadystate phase as indicated by the dash-dot line, the actual fusion power is increased and goes up over $3 \mathrm{GW}$ as shown by the solid line. The central electron density also increases from $1 \times 10^{20}$ to $1.5 \times 10^{20} \mathrm{~m}^{-3}$ in $\sim 20 \mathrm{~s}$ due to the abrupt increase in the fueling rate set at the maximum of $1 \times$ $10^{19} \mathrm{~m}^{-3} / \mathrm{s}$, but the ion temperature is kept almost constant at $\sim 30 \mathrm{keV}$. The heating power up to $100 \mathrm{MW}$ applied automatically keeps the ion temperature at the same level in the higher density. The toroidal beta value $\langle\beta\rangle$ also increases as shown by the dash-dot line at the same time as the fusion power and can be over the beta limit. As the

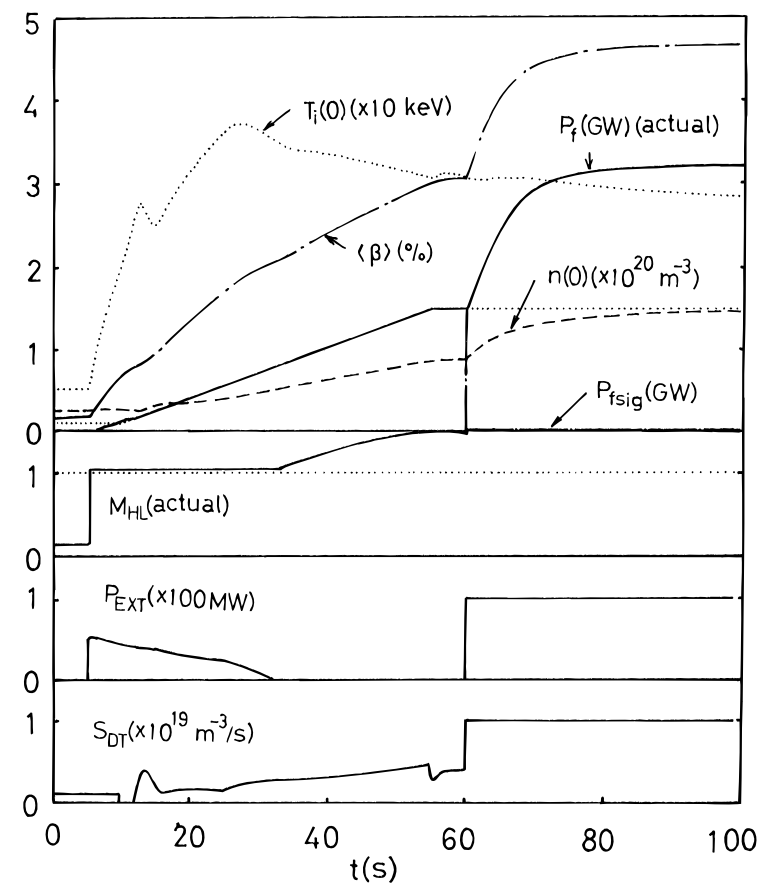

Fig. 2. Complete failure effect of neutron diagnostic system for the fusion power measurement $\left(\epsilon_{p n}=-1\right)$ on ignited operation for a set of $\left\{P_{E X T}(\mathrm{HL})\right.$ and $\left.S_{\mathrm{DT}}\left(P_{f}\right)\right\}$. The other diagnostic system is assumed to work perfectly unless otherwise noted. A neutron diagnostic failure takes place at $60 \mathrm{~s}$ in the steady-state phase with $\gamma_{\mathrm{HH}}=1.0$ over the ITER93HP scaling and $M_{\mathrm{HL} 0}=1.05$. The temperature is $T_{i}(0)$; the density is $n(0)$; the beta value is $\langle\beta\rangle$; the actual fusion power is $P_{f}$ (actual); the fusion power signal is $P_{f s i g}$; the actual H-mode indicator is $M_{\mathrm{HL}}$ (actual); the external heating power is $P_{E X T}$; and the fueling rate is $S_{\mathrm{DT}}$. beta value exceeds the limit of $\langle\beta\rangle_{\max } \sim 3.2 \%$ before reaching the maximum fusion power, it may lead to disruption or a soft beta limit. If the fast alpha contribution to the beta value is taken into account, the actual beta value increases quicker than this case, and then disruption may take place earlier. If the soft beta limit suppresses the fusion power surge, it would be desirable. However, this can be alleviated by the fail-safe control algorithm as discussed later in Sec. III.D.

We have examined sudden LOSE effects of neutron measurements depending on the burn phase when the LOSE takes place during the various ignition phases, such as (a) from the outset and during the fusion burn rise-up phase, steady-state phase, and shutdown phase, and (b) during the overignition phase by sudden increase in the confinement factor or during the subignited operation by a sudden decrease in the confinement factor. Regarding (a), LOSE of neutron measurements taking place from the outset during the fusion burn rise-up, steady-state, and shutdown phases leads to the actual fusion power slow surge as long as fueling is controlled by the fusion power through $S_{\mathrm{DT}}\left(P_{f}\right)$ after LOSE. Regarding (b), if LOSE takes place during the discharge with the higher confinement factor, for instance, $\gamma_{\mathrm{HH}}=1.3$, the final fusion power surge reaches $\sim 4.6 \mathrm{GW}$. Therefore, if it takes place during the overignition phase caused by a sudden increase in the confinement factor, the result would be a large fusion power surge. On the other hand, if LOSE takes place during the subignited operation with a smaller confinement factor, for instance, $\gamma_{\mathrm{HH}}=0.7$, the maximum fusion power is $2.1 \mathrm{GW}$ at $8 \mathrm{~s}$ after LOSE and stays at $1.7 \mathrm{GW}$ later. Thus, the increase in the fusion power due to LOSE is reduced in the subignited operation.

\section{III.B. Partial LOSE Effects in Neutron Measurements for the Control Algorithm of $\left\{P_{E X T}(\mathrm{HL})\right.$ and $\left.S_{\mathrm{DT}}\left(P_{f}\right)\right\}$}

If $50 \%$ of the neutron signals are lost at $60 \mathrm{~s}$, which may correspond to the loss of half the sight lines in the neutron source measurement $\left(\epsilon_{p n}=-0.5\right)$ such as neutron camera and microfission chamber, the actual fusion power similarly increases up to $\sim 3 \mathrm{GW}$ in $\sim 10 \mathrm{~s}$ as shown in Fig. 3. The fusion power signal drops down to $0.75 \mathrm{GW}$, half of the set value, and increases again in $10 \mathrm{~s}$ to the set value of $1.5 \mathrm{GW}$, as shown by the dashdot line for $P_{f s i g}$ in Fig. 3. The final actual fusion power of $3 \mathrm{GW}$ after the neutron diagnostic failure is just two times larger than the set value of $P_{f o}=1.5 \mathrm{GW}$. The heating power is not saturated at $100 \mathrm{MW}$, and the fueling is less than the maximum set value after the diagnostic failure.

As the measured fusion power signal $P_{f s i g}$ is the same as the set value of $P_{f o}=1.5 \mathrm{GW}$ after $70 \mathrm{~s}$, as shown by the dash-dot line, it is difficult to distinguish whether the signal failure takes place or not as long as the total signal is monitored. Therefore, each channel in the multiple sight lines should be monitored for detection of the signal 


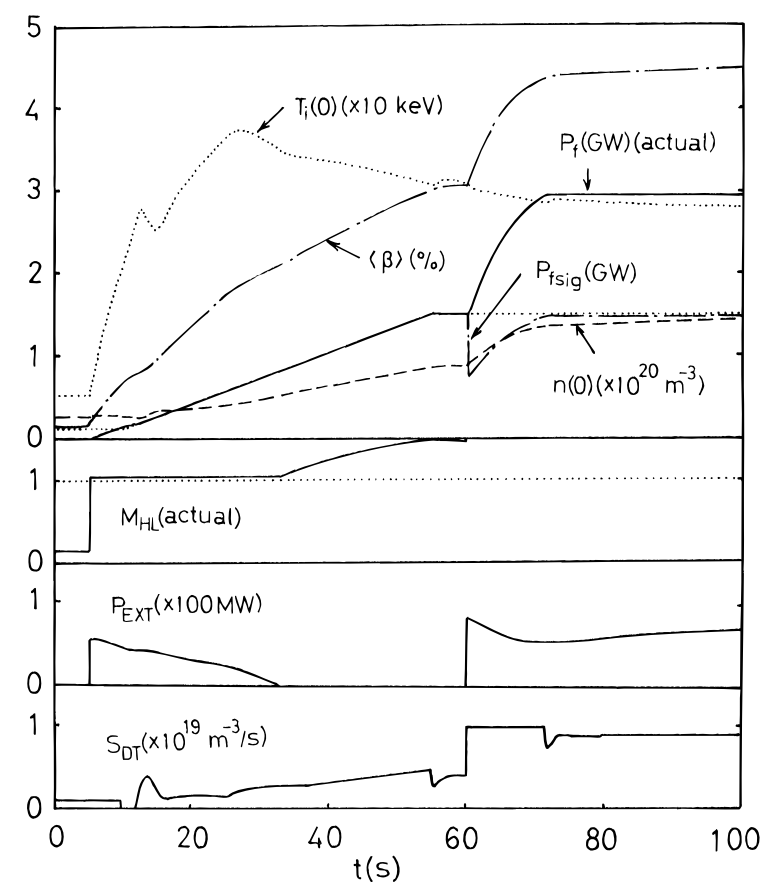

Fig. 3. Partial failure effect of neutron diagnostic system for the fusion power measurement $\left(\epsilon_{p n}=-0.5\right)$ on ignited operation for a set of $\left\{P_{E X T}(\mathrm{HL})\right.$ and $\left.S_{\mathrm{DT}}\left(P_{f}\right)\right\}$. The other diagnostics work perfectly.

failure. Upon detection of LOSE, for example, with $20 \%$ signal loss, as the fusion power signal is multiplied by $1 / 0.8$, the actual fusion power in the ignited operation might be at $\sim 1.87 \mathrm{GW}$.

\section{III.C. Measuring Error Effect of the Neutron Diagnostics on Ignition Access for the Control Algorithm of $\left\{P_{E X T}(\mathrm{HL})\right.$ and $\left.S_{\mathrm{DT}}\left(P_{f}\right)\right\}$}

When the neutron diagnostic system has an overestimated measuring error of $+10 \%$ from the outset, ignition cannot be accessed for $M_{\mathrm{HL} 0}=1.05$, as shown in Fig. 4a. This is because that $+10 \%$ overestimation in neutron measurements provides $10 \%$ less actual fusion power. As the alpha-heating and external heating power are also $10 \%$ less than the set value, the actual $\mathrm{H}$-mode indicator $M_{\mathrm{HL}}$ (actual) is smaller than the measured value and close to unity. Then the operating point tends to return to the $\mathrm{L}$ mode and is close to the marginal point, which eventually enters into the L mode. Fueling is supplied to try to keep the fusion power at the desired value, and the heating power is switched on to try to keep the $\mathrm{H}$ mode after return to the $\mathrm{L}$ mode.

If an overestimated measuring error of $+10 \%$ takes place at $60 \mathrm{~s}$ in the flat phase of the fusion power, the ignition state is maintained only for $\sim 114 \mathrm{~s}$, and then the $\mathrm{H}$ mode eventually returns to the $\mathrm{L}$ mode as shown in
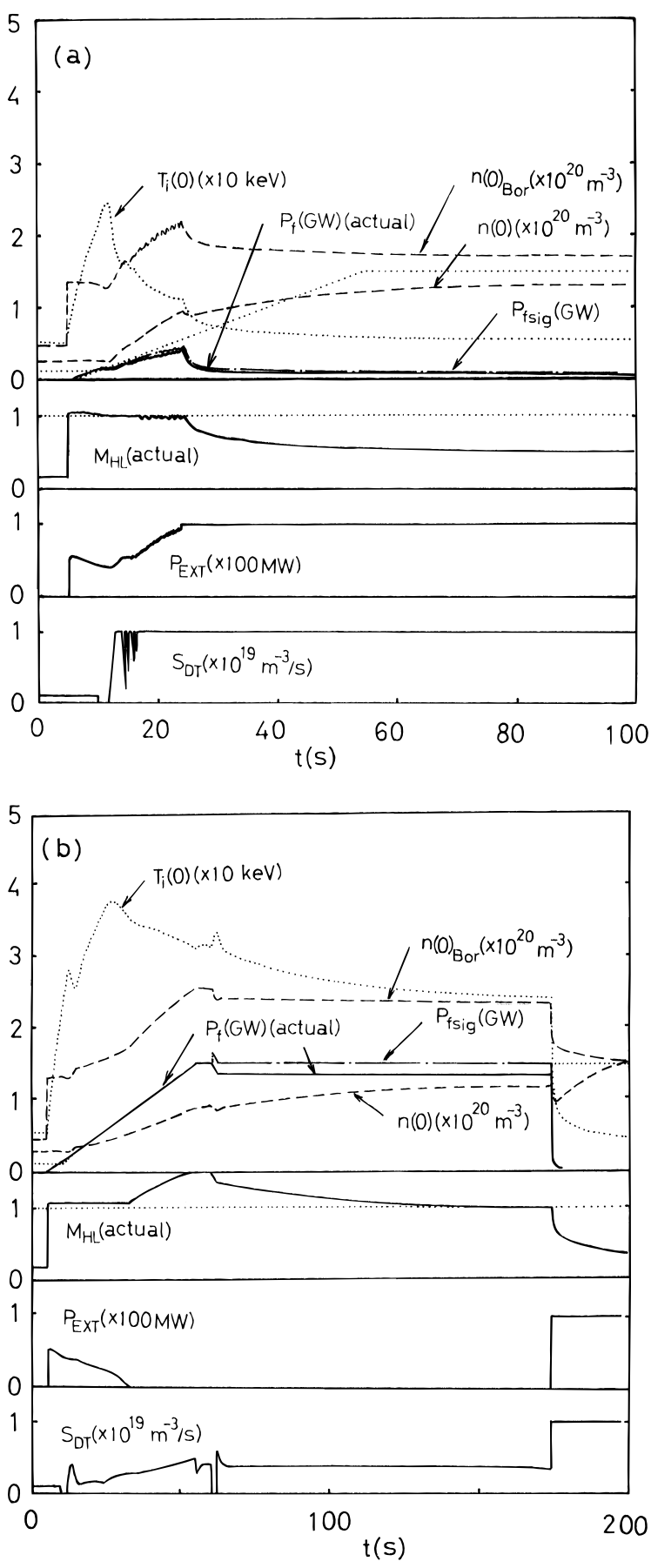

Fig. 4. The effect of $\epsilon_{p n}=+10 \%$ overestimated error in neutron diagnostics on ignited operation for $M_{\mathrm{HLO}}=1.05$ when the measuring error or the detector degradation takes place (a) from the outset and (b) at $t=60 \mathrm{~s}$.

Fig. 4b. As shown in this figure, as the Borrass density limit is larger than the actual density after LOSE for $25 \mathrm{~s}$, disruption could be avoided for a while. Here, the Borrass density limit $n_{B o r}(0)$ converted to the central density $^{31}$ is given by 


$$
\begin{aligned}
& n(0)_{\text {Bor }}\left[\times 10^{20} \mathrm{~m}^{-3}\right] \\
& \quad \approx 3.5\left(1+\alpha_{n}\right) \times 1.8 \frac{P_{\perp}^{0.53}\left[\mathrm{MW} / \mathrm{m}^{2}\right] B_{o}^{0.31}[\mathrm{~T}]}{\left(q_{95 \%} R_{o}[\mathrm{~m}]\right)^{0.22}}
\end{aligned}
$$

where $q_{95}$ is the safety factor at $95 \%$ of the magentic surface and taken as 2.4, $P_{\perp}$ is the mean heat flux across the separatrix calculated by $\left[\bar{P}_{h . n e t} V_{o}\right] / S_{o}$ with the net heating power, the plasma volume $V_{o}=2 \pi R \pi a^{2} \kappa$, and the plasma surface $S_{o}=2 \pi R 2 \pi a\left\{\left(1+\kappa^{2}\right) / 2\right\}^{0.5}$ in this study. Therefore, after the LOSE, fueling should be switched off externally, and density should be decreased. In this case, subignited operation cannot be done because the heating power is not correctly estimated for a feedback control. Therefore, in-situ calibration of the alpha-heating power signal is necessary for the calculation of the external heating power to keep the $\mathrm{H}$ mode.

On the other hand, when $-10 \%$ error in the neutron diagnostic system takes place from the outset for the $\mathrm{H}$-mode indicator $M_{\mathrm{HL} 0}=1.05$ the actual fusion power is larger than $10 \%$, and then $M_{\mathrm{HL}}$ (actual) is always $>1.05$. Therefore, the $\mathrm{H}$ mode and ignition can be maintained up to the end.

Thus, we have found that the allowable overestimated measuring error for ignited operation is related to the set value of the $\mathrm{H}$-mode indicator $M_{\mathrm{HL} 0}$, which is plotted in Fig. 5. Above the solid line with crosses, ignition cannot be accessed, and between the two solid lines with triangles and circles, the sawtooth-like fusion power is observed during ignition access. Below the line with circles, the smooth increase in fusion power can be ob-

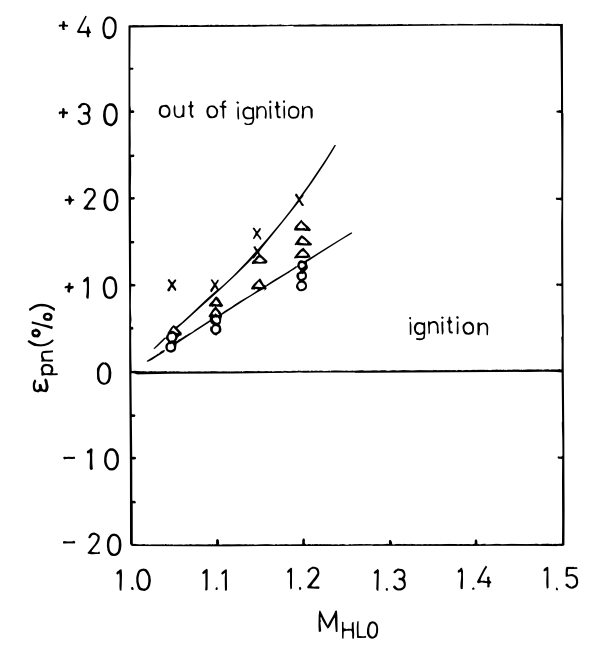

Fig. 5. Relationship of the measuring error and the H-mode indicator $M_{\mathrm{HL} 0}$ for ignited operation. The heating powers for subignited operation are $P_{E X T}(\mathrm{HL})=0 \mathrm{MW}$ $\left(\right.$ for $\left.M_{\mathrm{HLO}}=1.05\right), 6.1 \mathrm{MW}(1.10), 11.5 \mathrm{MW}$ (1.15), 22.8 MW (1.25), and 52.5 MW (1.5). tained. For ignited operation with $M_{\mathrm{HL} 0}=1.05$, allowable measuring error of the neutron diagnostics is as small as $\epsilon_{p n}=+3$ to $4 \%$. For $+10 \%$ error, $M_{\mathrm{HL} 0}$ should be larger than $\sim 1.15$. This result comes from the fact that the ignition is operated at the point close to the $\mathrm{H}-\mathrm{L}$ transition boundary. To operate at the larger $M_{\mathrm{HL} 0}$, however, we need the heating power, leading to the subignited operation as described in the caption of Fig. 5. Any underestimated error $\left(\epsilon_{p n}<0\right)$ is no problem, and ignition can be accessed because the actual fusion power is larger than the measured value.

Therefore, to operate near the H-L boundary, for instance, as in ITER, the neutron measurement system should have a better accuracy than $\pm 3 \%$. However, this value is too accurate for the diagnostics; in-situ calibration during the initial D-T phase may overcome this problem, as will be discussed in Sec. VII. A problem may be that the detector would be degraded with time during ignited operation. The foregoing results show the importance of the calibration of the neutron diagnostics or employment of detectors with a long lifetime and constant characteristics. Cross checking detectors by the other neutron diagnostics should also be done on a diagnostic network.

\section{III.D. Fail-Safe Operation in Ignited Operations with the Control Algorithm of $\left\{P_{E X T}(\mathrm{HL})\right.$ and $\min \left\{S_{\mathrm{DT}}\left(P_{f}\right)\right.$, $\left.\left.S_{\mathrm{DT}}(n), S_{\mathrm{DT}}\langle\langle\beta\rangle)\right\}\right\}$}

The fail-safe operation is possible by some means, for example, fueling stop for the first set of control algorithms of $\left\{P_{E X T}(\mathrm{HL})\right.$ and $\left.S_{\mathrm{DT}}\left(P_{f}\right)\right\}$. However, the second set of control algorithms of $\left\{P_{E X T}(\mathrm{HL})\right.$ and $\min \left\{S_{\mathrm{DT}}\left(P_{f}\right), S_{\mathrm{DT}}(n)\right.$, $\left.\left.S_{\mathrm{DT}}(\langle\beta\rangle)\right\}\right\}$ shows the inherently fail-safe operation because many diagnostics can back up fueling when one other diagnostic system fails.

\section{III.D.1. The case of LOSE in Neutron Diagnostics During the Fusion Burn Rise-Up Phase}

If the fusion power signal becomes zero level at $60 \mathrm{~s}$ for the control algorithm of a set of $\left\{P_{E X T}(\mathrm{HL})\right.$ and $\left.S_{\mathrm{DT}}\left(P_{f}\right)\right\}$, the fueling should be switched off quickly after the LOSE of the neutron diagnostics. Figure 6a shows the slow shutdown by switching off fueling at $2 \mathrm{~s}$ after the null signal of the fusion power is detected. The fusion power initially increases and then decreases after $2 \mathrm{~s}$ relatively slowly to zero level in $\sim 40 \mathrm{~s}$. If detection of the LOSE is delayed, the peak fusion power increases more and exceeds the allowable value. In this case, the heating power is not switched off; otherwise, the $\mathrm{H}$ mode returns to the L mode quickly, and the decay time of the fusion power would be much shorter.

On the other hand, for the fail-safe control algorithm of $\left\{P_{E X T}(\mathrm{HL})\right.$ and $\left.\min \left\{S_{\mathrm{DT}}\left(P_{f}\right), S_{\mathrm{DT}}(n), S_{\mathrm{DT}}(\langle\beta\rangle)\right\}\right\}$ with the Greenwald density limit of $n(0)_{G W} \sim 1.3 \times 10^{20} \mathrm{~m}^{-3}$ and the maximum beta limit $\langle\beta\rangle_{\max }=3.2 \%$, even if the 

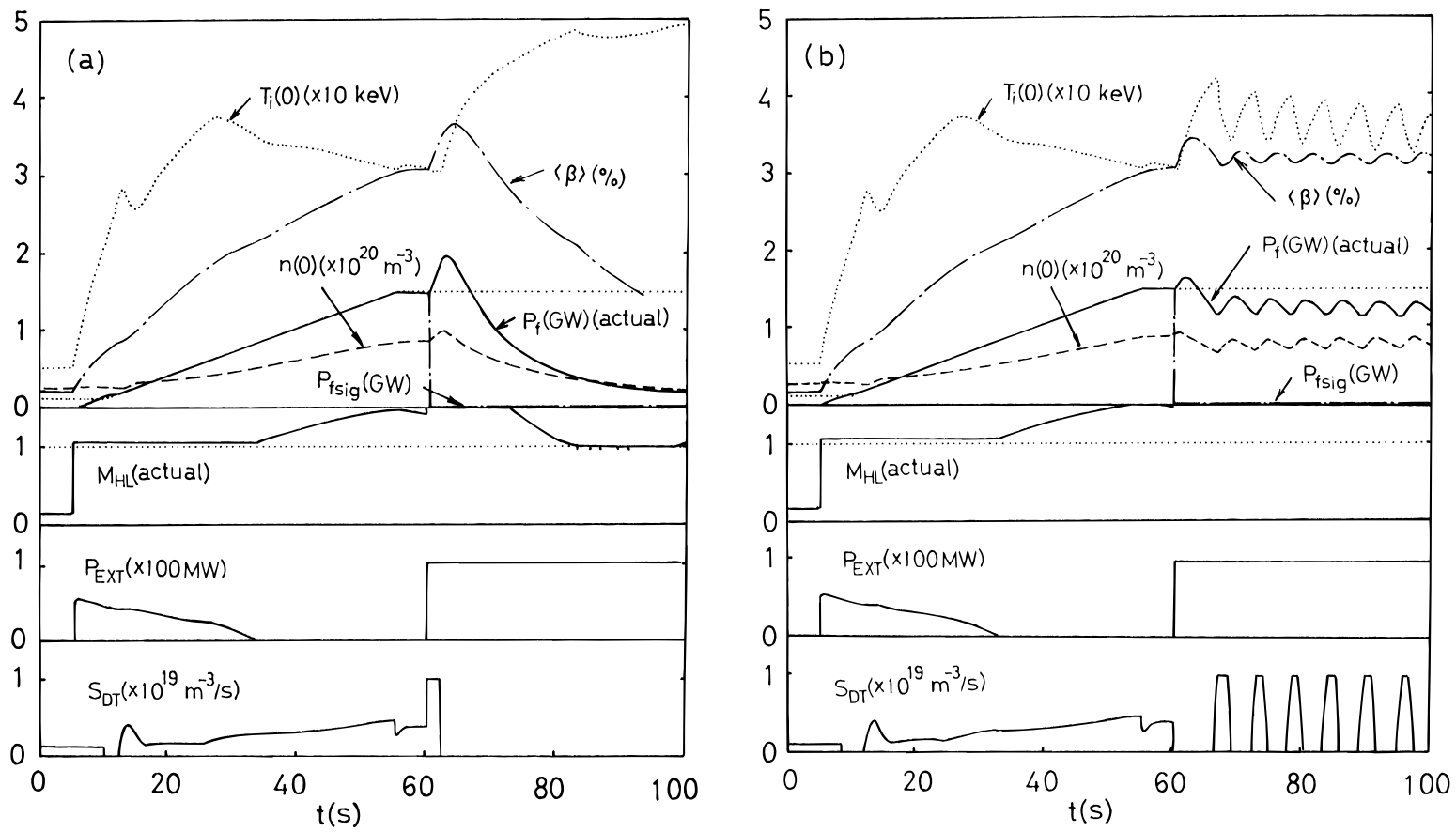

Fig. 6. (a) Fail-safe operation of the ignited operation for the control algorithm of $\left\{P_{E X T}(\mathrm{HL})\right.$ and $\left.S_{\mathrm{DT}}\left(P_{f}\right)\right\}$ by the fueling switch off at $2 \mathrm{~s}$ after LOSE of the neutron measurement at $60 \mathrm{~s}$ and (b) fail-safe operation of the ignited operation for the control algorithm of $\left\{P_{E X T}(\mathrm{HL})\right.$ and $\left.\min \left\{S_{\mathrm{DT}}\left(P_{f}\right), S_{\mathrm{DT}}(n), S_{\mathrm{DT}}(\langle\beta\rangle)\right\}\right\}$ with the Greenwald density limit $n(0)_{G W} \sim 1.3 \times 10^{20} \mathrm{~m}^{-3}$ and the maximum beta limit $\langle\beta\rangle_{\max }=3.2 \%$.

fusion power signal is dropped to zero at $60 \mathrm{~s}$, the fusion power does not increase but oscillates at $\sim 1.5 \mathrm{GW}$ as shown in Fig. 6b. Here, as the beta value is limited by $3.2 \%$ and the density is far below the Greenwald density limit $n(0)_{G W} \sim 1.3 \times 10^{20} \mathrm{~m}^{-3}$, the fusion power is regulated by the beta value through $S_{\mathrm{DT}}(\langle\beta\rangle)$. Thus, we see that the variable fusion power control algorithm works for a fail-safe ignited operation in a reactor including ITER when the neutron diagnostic system has a failure. The parameter oscillation after $60 \mathrm{~s}$ has also been observed for the beta value limitation as pointed out before. ${ }^{20}$ The beta measurements by the diamagnetic loops should be reliable for this control algorithm.

If the maximum density is set to the lower value, the fusion power is regulated by the density, but the parameter oscillation has not been observed. After detecting the neutron diagnostic failure, the set value of the density $n(0)_{G W}$ can be lowered. As long as the interferometry is functional, the term of $S_{\mathrm{DT}}(n)$ limits the fueling, and no fusion power surge is observed. Therefore, this control algorithm has inherently a fail-safe function without relying on the backup system of the neutron diagnostics. Thus, the interferometer system can also work as a backup diagnostic system for the neutron diagnostics.

\section{III.D.2. The Case of LOSE in Neutron Diagnostics from the Outset}

When neutron diagnostics have a failure from the outset, the beta value quickly increases to $4.5 \%$ and the fusion power increases to $3.2 \mathrm{GW}$ in $10 \mathrm{~s}$, as shown in Fig. 7a for the control algorithm of $\left\{P_{E X T}(\mathrm{HL})\right.$ and $\left.S_{\mathrm{DT}}\left(P_{f}\right)\right\}$. To prevent the excessive high fusion power and the beta limit disruption, we use the fail-safe control algorithm of $\left\{P_{E X T}(\mathrm{HL})\right.$ and $\min \left\{S_{\mathrm{DT}}\left(P_{f}\right), S_{\mathrm{DT}}(n)\right.$, $\left.\left.S_{\mathrm{DT}}(\langle\beta\rangle)\right\}\right\}$ with $\langle\beta\rangle_{\max }=3.2 \%$ and $n(0)_{G W} \sim 1.3 \times$ $10^{20} \mathrm{~m}^{-3}$. Initially the density is suppressed; then the temperature increases up to $\sim 50 \mathrm{keV}$ and then slowly decreases. Ignition can be maintained with the beta value of $\sim 3.2 \%$, as shown in Fig. $7 b$, and the fusion power is increased initially up to $\sim 2.0 \mathrm{GW}$, and then it is decreased and regulated $\sim 1.2 \mathrm{GW}$. After reaching the steady state, ignition can be terminated slowly by switching off the fueling with keeping the heating power. Plasma parameters are oscillating due to the proportional feedback control by the beta value.

\section{III.D.3. The Case of LOSE in Neutron Diagnostics During the Shutdown Phase}

In Sec. III.D.1, we have seen that a fueling stop is very effective to avoid the fusion power surge caused by LOSE in fusion power measurements during the ignition access and steady-state phases. During the normal fusion power shutdown phase with the control algorithm of $\left\{P_{E X T}(\mathrm{HL})\right.$ and $\left.S_{\mathrm{DT}}\left(P_{f}\right)\right\}$, as fueling is very small for smooth fusion power decay, it is possible to decrease the fusion power slowly by switching off the fueling. If LOSE in the neutron diagnostics takes place at $1020 \mathrm{~s}$ during the fusion power shutdown phase, as shown in Fig. 8, the 

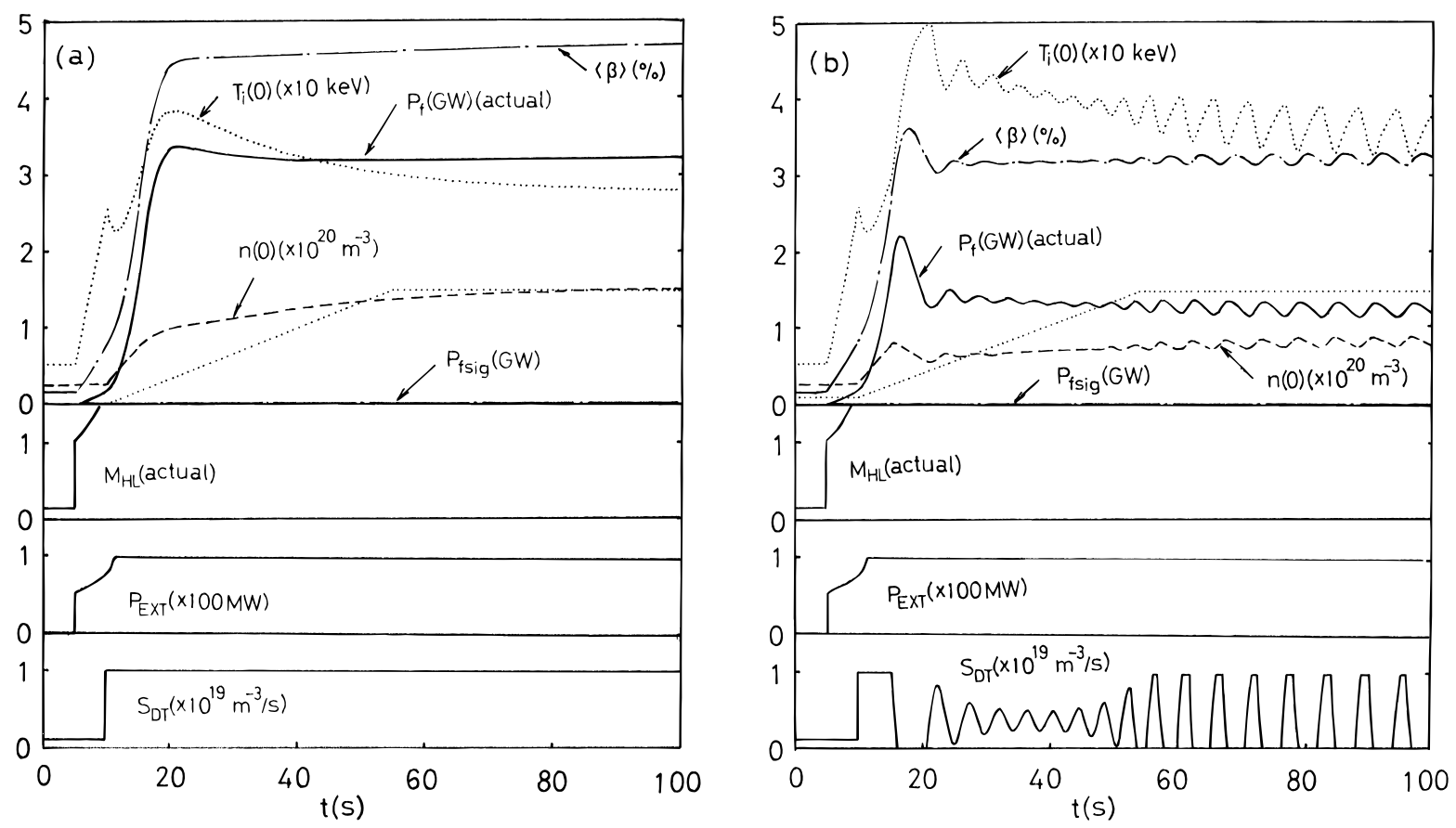

Fig. 7. (a) Ignited operation when LOSE of the neutron measurement has a failure from the outset for the control algorithm of $\left\{P_{E X T}(\mathrm{HL})\right.$ and $\left.S_{\mathrm{DT}}\left(P_{f}\right)\right\}$ and (b) Corresponding fail-safe operation of the ignited operation to (a) for the control algorithm of $\left\{P_{E X T}(\mathrm{HL})\right.$ and $\left.\min \left\{S_{\mathrm{DT}}\left(P_{f}\right), S_{\mathrm{DT}}(n), S_{\mathrm{DT}}(\langle\beta\rangle)\right\}\right\}$ with the Greenwald density limit $n(0)_{G W} \sim 1.3 \times 10^{20} \mathrm{~m}^{-3}$ and the maximum beta limit $\langle\beta\rangle_{\text {max }}=3.2 \%$.

fusion power surge is not induced because there is no fueling. The heating power slowly increases to maintain the $\mathrm{H}$ mode and prevent $\mathrm{H}-\mathrm{L}$ back transition during the shutdown phase and abruptly jumps up when the neutron diagnostic failure takes place at $t=1020 \mathrm{~s}$, as indicated by $P_{f s i g}=0$. The fusion power slightly increases after LOSE and decays smoothly in $\sim 50 \mathrm{~s}$. We should note that in the normal shutdown phase, the fusion power decays linearly along the dotted line if the fueling is controlled by $S_{\mathrm{DT}}\left(P_{f}\right)$. It is concluded that fueling should be always switched off during the normal fusion burn shutdown phase from the safe operating point of view.

\section{LOSE EFFECT IN BOLOMETER DIAGNOSTICS ON IGNITION ACCESS}

When the bolometer has a failure and its signal becomes zero, as $P_{b s i g}=P_{b}\left(1+\epsilon_{b}\right) \rightarrow 0$ with $\epsilon_{b} \rightarrow-1$, during the ignition access phase with the control algorithm of $\left\{P_{E X T}(\mathrm{HL})\right.$ and $\left.S_{\mathrm{DT}}\left(P_{f}\right)\right\}$, the fusion power and temperature quickly decrease due to instantaneous decrease in the heating power $P_{E X T}(\mathrm{HL})$, as shown in Fig. 9. Fueling is increased by the feedback control because the fusion power is smaller than the set value.

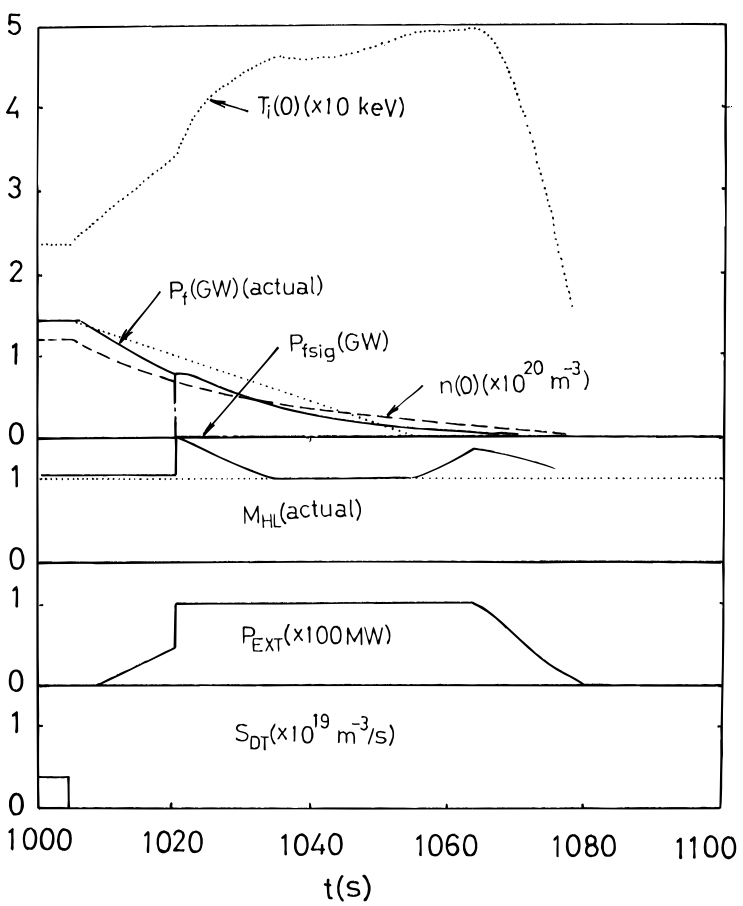

Fig. 8. LOSE effect (after $t=1020 \mathrm{~s}$ ) of the neutron diagnostics during the fusion power shutdown phase without fueling. 


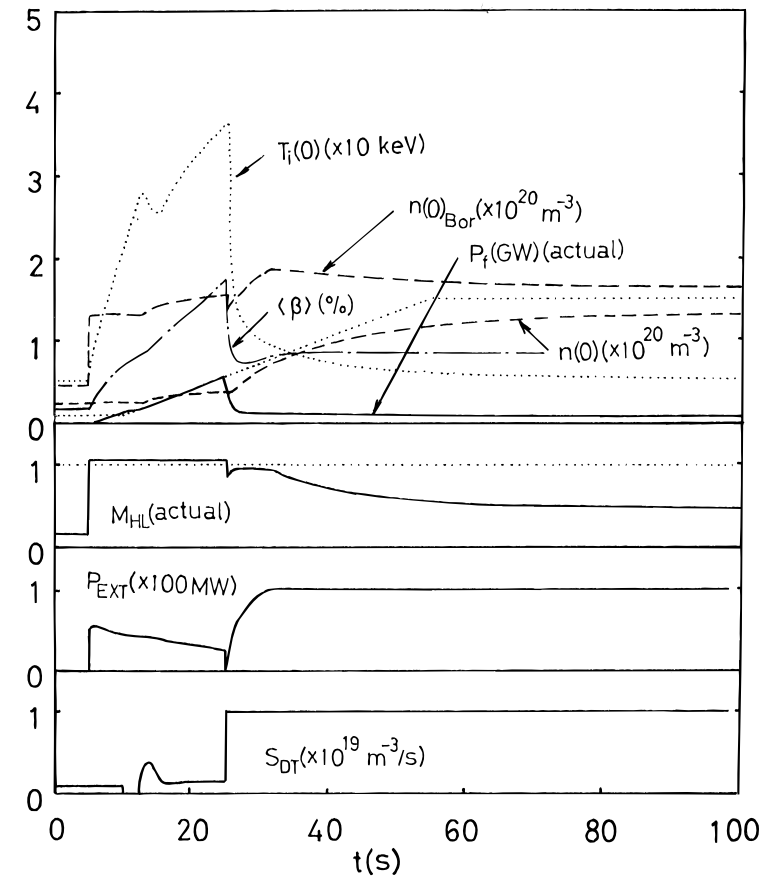

Fig. 9. The effect of bolometer diagnostic failure $\left(\epsilon_{p b}=-1\right)$ on the ignited operation during the ignition access heating phase.

The $\mathrm{H}$ mode returns to the $\mathrm{L}$ mode at the same time when the bolometer signal is decreased due to a failure. Immediately after the transition to the L mode, the heating power is applied to try to keep the $\mathrm{H}$ mode, but the $\mathrm{H}$ mode cannot be regained due to the increase in the density by excessive fueling and the decrease in the alpha heating as seen on the actual H-mode indicator $M_{\mathrm{HL}}$ (actual). As ignition cannot be reached with the $\mathrm{L}$ mode, the plasma parameter cannot evolve, and the lowfusion-power state persists with the L mode. Even when the operating point returns to the $\mathrm{L}$ mode and the fusion power quickly decays, disruption could be avoided because the Borrass density limit is larger than the actual density due to automatic switching on of the heating power. Therefore, this type of diagnostic failure is on the safer side. We have further found that ignition cannot be accessed when the bolometer diagnostic failure worse than $\epsilon_{b}<-0.4$ takes place during the heating phase with $M_{\mathrm{HL} 0}=1.05$.

On the other hand, if a complete LOSE in the bolometry $\left(\epsilon_{b}=-1\right)$ takes place in the steady state in the ignited operation for $P_{E X T}(\mathrm{HL})=0$, ignition no longer terminates for $M_{\mathrm{HL} 0}=1.05$. This is because the heating power is further reduced to the negative value and hence set to zero, which does not change any parameters. If complete LOSE in the bolometry $\left(\epsilon_{b}=-1\right)$ takes place during the shutdown phase, the heating power $P_{E X T}(\mathrm{HL})$ is reduced. Then, the $\mathrm{H}$ mode returns to the $\mathrm{L}$ mode, and ignition terminates quickly as observed during the fusion power rise-up phase.

In the case of the subignited operation with the lower confinement factor, $\gamma_{\mathrm{HH}}=0.7$, a small degradation in the bolometer detector of $\epsilon_{b}=-15 \%$ can terminate the ignited operation. However, disruption could be avoided in this case because the Borrass density limit is always larger than the electron density after ignition termination.

Even if the bolometer signal shows the abnormally large signal of $\epsilon_{b}=+100 \%$ at $25 \mathrm{~s}$, the heating power is increased, and ignition is reached for the control algorithm of $\left\{P_{E X T}(\mathrm{HL})\right.$ and $\left.S_{\mathrm{DT}}\left(P_{f}\right)\right\}$. However, the heating power is slowly increased again after $70 \mathrm{~s}$, and subignited operation eventually results.

\section{FRINGE JUMP EFFECTS IN INTERFEROMETER MEASUREMENTS ON IGNITED OPERATION}

While a Faraday rotation method has been developed for ITER density measurements ${ }^{32,33}$ to avoid a fringe counting error taking place in the interferometry, we consider a fringe-counting-error effect on the ignited operation when the classical fringe-counting method would be used.

For the control algorithm of $\left\{P_{E X T}(\mathrm{HL})\right.$ and $\left.S_{\mathrm{DT}}\left(P_{f}\right)\right\}$, if LOSE of the interferometry $\left(\epsilon_{n}=-1\right.$, the fringe jumpdown to zero) takes place during the ignition access phase at $25 \mathrm{~s}$, the heating power $P_{E X T}(\mathrm{HL})$ given by Eq. (2) is decreased down to the negative value, which is set to the zero. Therefore, the fusion power drops and ignition access is prevented. Thus we see that the operation is terminated for LOSE in the interferometry during the ignition access phase. Even if the signal of the interferometry has an underestimated measuring error of $\epsilon_{n}=-7 \%$, the $\mathrm{H}$ mode returns to $\mathrm{L}$ mode due to a small decrease in the heating power, as shown in Fig. 10a. Then the fusion power drops, and fueling is increased by the feedback control, which prevents the ignition access because the $\mathrm{H}$ mode cannot be regained. The actual density $n(0)$ is shown by the dashed line, and the measured density $n(0)_{\text {sig }}$ is smaller by $7 \%$ than that shown by the dash-dot line. Thus, the measuring error of the density with $\epsilon_{n}<-7 \%$ leads to ignition termination, as discussed in the measuring error effect of the neutron diagnostics of $\epsilon_{p n}=+10 \%$ in Sec. III.C.

If the fringe jump-down in the interferometry takes place after reaching ignition at $60 \mathrm{~s}$, the heating power is already switched off, and no effect exists on ignited operation. On the other hand, if it takes place during the fusion power shutdown phase, the heating power is switched off; then the $\mathrm{H}$ mode cannot be maintained, and the fusion power quickly decays as observed during the ignition access phase.

If the fringe jump-up takes place more than twice, $\epsilon_{n}=+100 \%$ at $25 \mathrm{~s}$ during the ignition access phase, as 

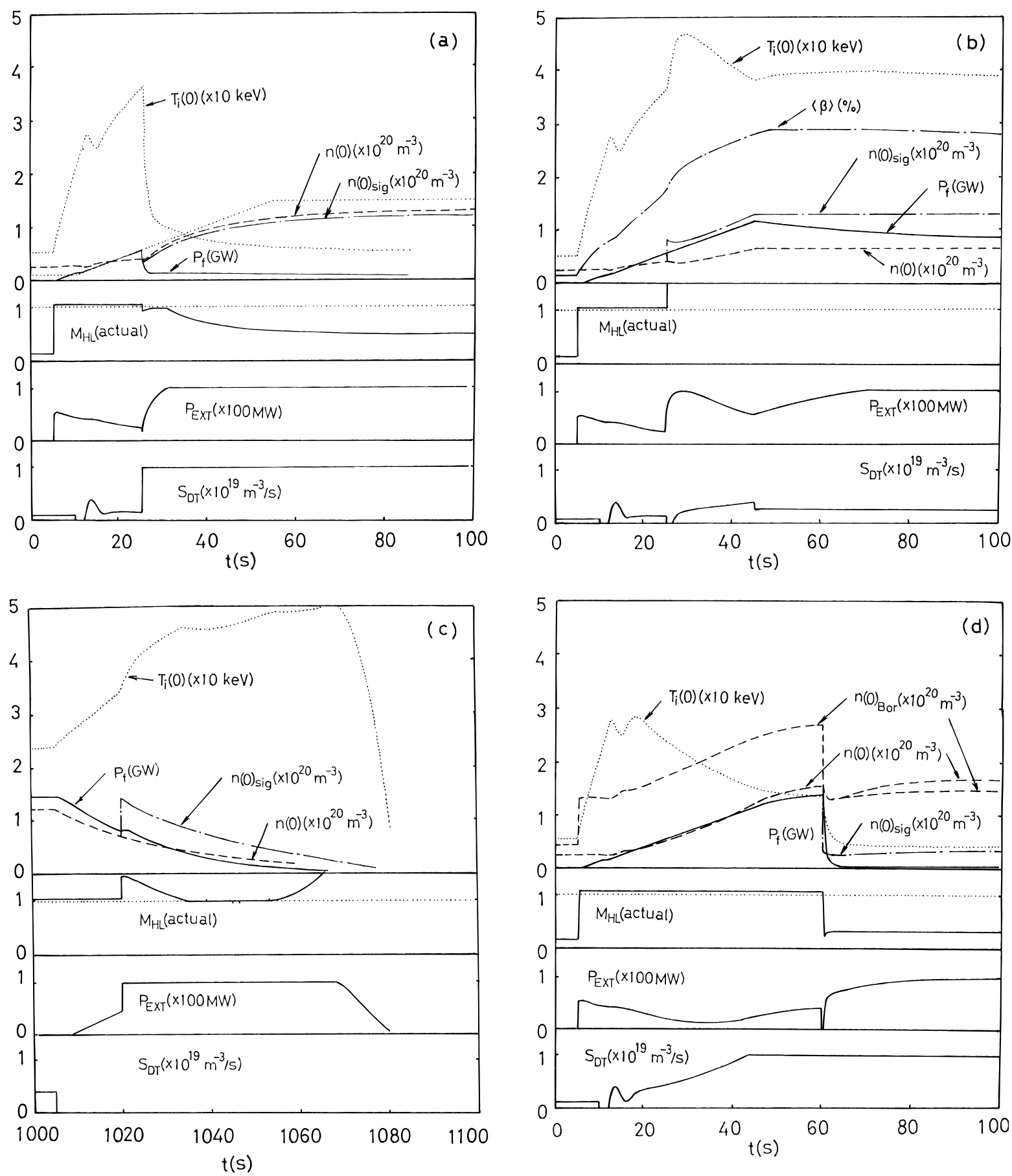

Fig. 10. The effect of interferometer failure on the ignited operation: (a) $\epsilon_{n}=-7 \%$ at $t=25 \mathrm{~s}$ during the ignition access phase, (b) $\epsilon_{n}=+100 \%$ at $t=25 \mathrm{~s}$ during the ignition access phase for the control algorithm of $\left\{P_{E X T}(\mathrm{HL})\right.$ and $\min \left\{S_{\mathrm{DT}}\left(P_{f}\right)\right.$, $\left.\left.S_{\mathrm{DT}}(n), S_{\mathrm{DT}}(\langle\beta\rangle)\right\}\right\}$, (c) $\epsilon_{n}=+100 \%$ at $t=1020 \mathrm{~s}$ during the ignition shutdown phase for the control algorithm of $\left\{P_{E X T}(\mathrm{HL})\right.$ and $\left.S_{\mathrm{DT}}\left(P_{f}\right)\right\}$, and $(\mathrm{d}) \epsilon_{n}=-80 \%$ at $t=60 \mathrm{~s}$ during the subignited operation with $\gamma_{\mathrm{HH}}=0.7$ for the control algorithm of $\left\{P_{E X T}(\mathrm{HL})\right.$ and $\left.S_{\mathrm{DT}}\left(P_{f}\right)\right\}$. The Borrass density limit is lower than the density after ignition termination.

indicated by the dash-dot line $n(0)_{s i g}$, the heating power $P_{E X T}(\mathrm{HL})$ is increased, and fueling is decreased, as shown in Fig. 10b, where the control algorithm of $\left\{P_{E X T}(\mathrm{HL})\right.$ and $\left.\min \left\{S_{\mathrm{DT}}\left(P_{f}\right), S_{\mathrm{DT}}(n), S_{\mathrm{DT}}(\langle\beta\rangle)\right\}\right\}$ has been used with $\langle\beta\rangle_{\max }=3.2 \%$ and $n(0)_{G W} \sim 1.3 \times 10^{20} \mathrm{~m}^{-3}$. At the same time, the $\mathrm{H}$-mode indicator and the temperature increase, and then the beta value increases. Ignited operation with fusion power $<1.5 \mathrm{GW}$ and the beta value 
of $\sim 2.9$ can be maintained after $40 \mathrm{~s}$ because the error signal of the density $n(0)_{\text {sig }}$ regulates fueling by fringe jump-up, which is limited by $n(0)_{G W}$.

If the fringe jump-up takes place at $t=1020 \mathrm{~s}$ during the shutdown phase without fueling, the fusion power decays with a small bump at $1020 \mathrm{~s}$, as shown in Fig. 10c for the first control algorithm of $\left\{P_{E X T}(\mathrm{HL})\right.$ and $\left.S_{\mathrm{DT}}\left(P_{f}\right)\right\}$. The temperature increases up to $50 \mathrm{keV}$ due to the heating power and low density. Thus, the fusion power can be terminated slowly.

In the case of the subignited operation with the lower confinement factor, $\gamma_{\mathrm{HH}}=0.7$, the fringe jump-down of $\epsilon_{n}=-7 \%$ at $60 \mathrm{~s}$ as discussed earlier can terminate the ignited operation. Disruption may be avoided down to $\epsilon_{n}>-75 \%$ because the Borrass density limit is larger than the electron density after ignition termination. However, too much fringe jump-down, such as $\epsilon_{n}=-80$ to $-100 \%$, makes the heating power lower through $P_{E X T}(\mathrm{HL})$ after ignition termination, and then disruption could be induced due to the smaller Borrass density limit controlled by the density signal with fringe jump-down as shown in Fig. 10d with $\epsilon_{n}=-80 \%$. This subignited operation should be done carefully for the failure in the interferometry.

Thus, we have found that LOSE (fringe jump-down) of the interferometry leads to termination of ignited operation, and the abnormally large signal (fringe jumpup) can be controlled by the fail-safe control algorithm of $\left\{P_{E X T}(\mathrm{HL})\right.$ and $\left.\min \left\{S_{\mathrm{DT}}\left(P_{f}\right), S_{\mathrm{DT}}(n), S_{\mathrm{DT}}(\langle\beta\rangle)\right\}\right\}$. Therefore, it is concluded that its impact of interferometry diagnostic failure on ignited operation can be small except for the subignited operation.

\section{IGNITED OPERATIONS WITHOUT LOST ALPHA DETECTORS}

So far, we have considered the diagnostic failure effect on ignited operations. Similarly we can consider the loss of signal in the lost alpha detector. However, it has been recognized that it may be difficult to implement the lost alpha detector into a reactor including ITER due to the incompleteness of detector developments ${ }^{34}$ despite active research. ${ }^{35}$ Therefore, in this section, we assume that the lost alpha detector is not installed for feedback control of fusion burn, and only the infrared (ir) camera would be used to monitor the first-wall temperature rise-up due to alpha particle loss.

In this study, we consider the presumed value effect of the alpha confinement fraction (alpha-particle heating efficiency $\eta_{\alpha}$ ) on ignition access and ignited operation. While the alpha-heating power involved in the external heating power calculated by Eq. (2) is determined by the presumed set value of $\eta_{\alpha}$ (set) as given by $\bar{P}_{\alpha}=f_{\mathrm{D}} f_{\mathrm{T}} 3.52 \eta_{\alpha}(\mathrm{set})\langle\sigma v\rangle_{\mathrm{DT}} 1.6 \times 10^{-13} n(0)^{2}$ instead of the measured value, the alpha confinement fraction in the power balance Eq. (A.3) in the Appendix is given by the actual value $\eta_{\alpha}$ (actual).

For the presumed set value of $\eta_{\alpha}(\mathrm{set})=0.90$, ignition access is shown in Fig. 11a for the actual value of the alpha confinement fraction $\eta_{\alpha}($ actual $)=0.97$. The heating
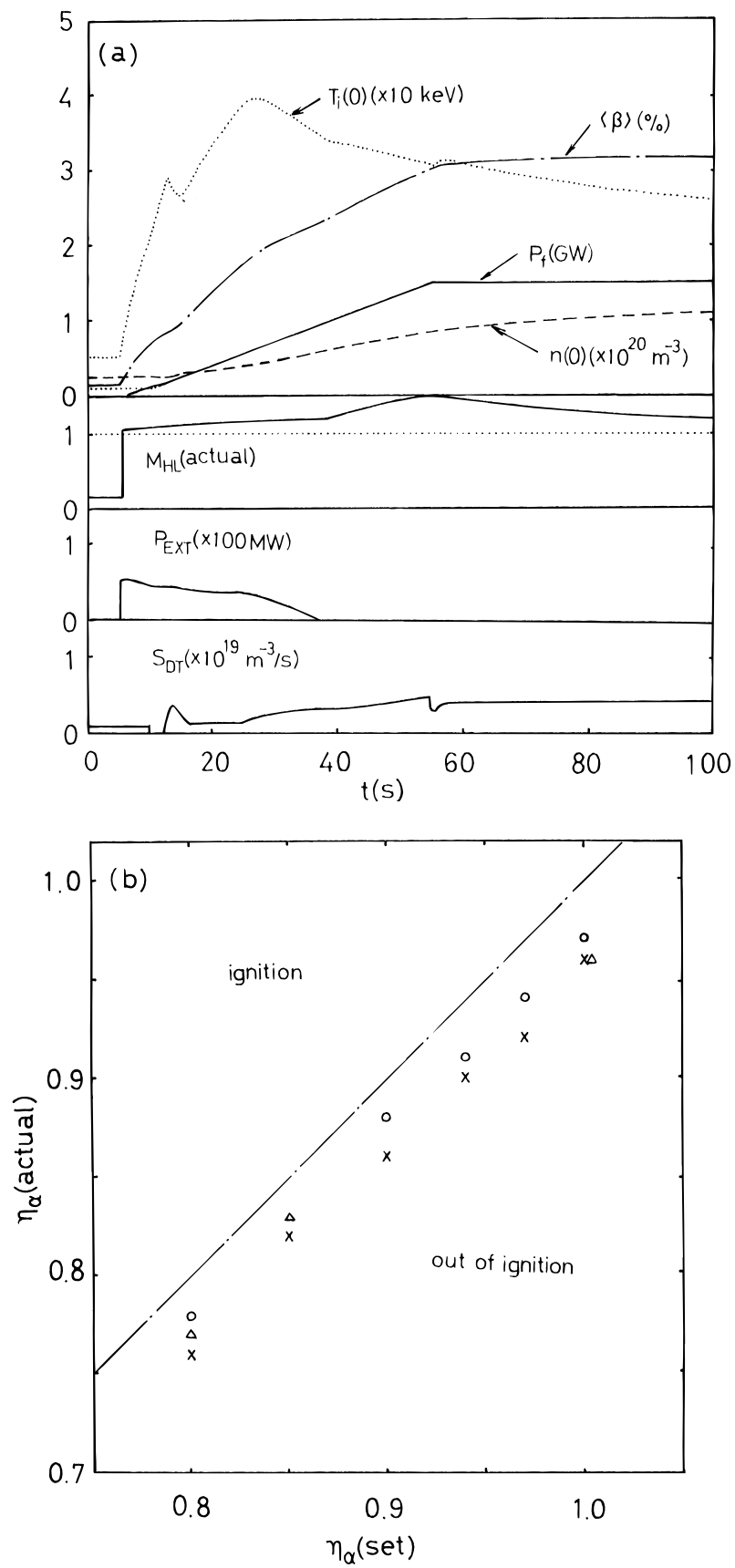

Fig. 11. (a) Ignition access with the set value of the alpha confinement fraction of $\eta_{\alpha}(\mathrm{set})=0.9$ for the case of $\eta_{\alpha}(\mathrm{ac}-$ tual $)=0.97$, and (b) the effect of the presumed alpha confinement fraction instead of the lost alpha detector measurements. The dash-dot line indicates the line with $\eta_{\alpha}($ set $)=\eta_{\alpha}$ (actual). 
power is larger than that in the case of $\eta_{\alpha}($ set $)=\eta_{\alpha}$ (actual) $=0.97$. Therefore, the H-mode indicator is larger during the heating phase; then there is more room for the parameter change in the alpha-confinement fraction.

As the actual alpha-confinement fraction is decreased, ignition cannot be reached. Therefore, ignition and outof-ignition regimes can be distinguished as a function of the actual alpha-confinement fraction $\eta_{\alpha}$ (actual) and the set value $\eta_{\alpha}$ (set), as plotted in Fig. 11 b. For $\eta_{\alpha}($ set $)=0.90$ set from the discharge outset, ignition can be maintained when the actual alpha-confinement fraction is reduced down to $\eta_{\alpha}$ (actual) $\sim 0.88$, above which ignition can be maintained. Similarly, for $\eta_{\alpha}(\mathrm{set})=0.97$, ignition can be maintained down to $\eta_{\alpha}($ actual $)=0.94$. The dash-dot line shows the line with $\eta_{\alpha}($ set $)=\eta_{\alpha}$ (actual). Therefore, the smaller set value of the alpha-confinement fraction is more robust to the change in the alpha-confinement fraction.

\section{DISCUSSION}

We have found that fueling is most critical for the safely ignited operation. Its maximum value should not be surpassed when some failure takes place. Fusion power determining fueling can be measured by the microfission chamber, ${ }^{36,37}$ the flux monitor by the fission chamber, ${ }^{38}$ and the neutron cameras. ${ }^{39}$ Therefore, if these diagnostics are connected in parallel for fueling and controlled by $\min \left\{S_{\mathrm{DT}}\left(P_{f, \text { fission chamber }}\right), S_{\mathrm{DT}}\left(P_{f, \text { flux monitor }}\right)\right.$, and $\left.S_{\mathrm{DT}}\left(P_{f, \text { neutron camera }}\right)\right\}$, ignited operation would be more safe for the failure of neutron diagnostics. On the other hand, control of the heating power is not so critical when the diagnostic failure takes place. Automatic application of the maximum heating power of $100 \mathrm{MW}$ after LOSE is a safe function because it can maintain the $\mathrm{H}$ mode and prevent the fast parameter change induced by the transition to the L mode.

So far, a neutron diagnostic system has been used for deriving both the fusion power and alpha-heating power. When the separate neutron diagnostic system has been used for each measurement, the consequences depend the following two cases. This is calculated by replacing $\epsilon_{p n} \rightarrow \epsilon_{p \alpha}$ in Eq. (2) and $\epsilon_{p n} \rightarrow \epsilon_{p f}$ in Eq. (3):

1. When only the neutron detector for the alphaheating power measurement has a failure in any phase, such as $\epsilon_{p f}=0$ and $\epsilon_{p \alpha}=-1$, the heating power is increased up to $100 \mathrm{MW}$, but fueling is functional. Therefore, the fusion power is controlled as a desired value, but the temperature is increased up to $35 \mathrm{keV}$, and the density is decreased down to $0.9 \times 10^{20} \mathrm{~m}^{-3}$. Therefore, the consequence is on the safer side.

2. When only the neutron detector for the fusion power measurement has a failure in any phase such as $\epsilon_{p f}=-1$ and $\epsilon_{p \alpha}=0$, fueling is suddenly increased while the heating power is switched off. Therefore, the fusion power surge up to $3.3 \mathrm{GW}$ takes place by increase in the density. Therefore, this case corresponds to the case demonstrated in Sec. III.A.

When both the neutron diagnostics have a failure at the same time, the consequence is the same as discussed already in Sec. III.A.

Numerical comparison, using the relationship of $P_{f}=\left(\bar{P}_{\alpha} / \eta_{\alpha}+\bar{P}_{n}\right) V_{o}=5\left(\bar{P}_{\alpha} / \eta_{\alpha}\right) V_{o}=5 f_{\mathrm{D}} f_{\mathrm{T}} n(0)^{2} \times$ (3.52) $\overline{\langle\sigma v\rangle_{\mathrm{DT}}}\left(T_{i}\right) \times 1.6 \times 10^{-13} V_{o}$, with the other plasma parameter measurements, should be done in parallel during feedback control. For this purpose, the alpha density fraction $f_{\alpha}$ and impurity density fraction $f_{i m p}$ should be measured to obtain deuterium and tritium density fractions $f_{\mathrm{D}}, f_{\mathrm{T}}$ with the relationship $f_{\mathrm{T}}=f_{\mathrm{D}}=\left(1-2 f_{\alpha}-4 f_{\mathrm{Be}}-Z f_{\text {imp }}\right) / 2$, and the ion temperature and profile should be measured to obtain $\overline{\langle\sigma v\rangle_{\mathrm{DT}}}\left(T_{i}\right)$. If the measured fusion power is largely different from the numerical value based on parameter measurements, we may detect some failure in the neutron diagnostics. Therefore, the numerical estimation with other diagnostics may work as a backup diagnostic system, and a diagnostic network system should be developed further for a fail-safe ignited operation in a tokamak reactor, including ITER.

So far, we have considered the case of the failure of the diagnostic systems of the neutron source measurements, bolometers, and interferometers. A lost alpha detector can be removed from the feedback control system while the detector is being prepared for physics measurements and first-wall monitoring. In addition to this type of failure, the failure effect of such a cable disconnection should be considered. After diagnostic failure the heating power was always applied, as seen in present analyses, and such a function can avoid the disruption associated with the Borrass density limit. Therefore, if the cable or line to the feedback controller for the heating power system from the diagnostic systems is disconnected or malfunctional, or if the feedback controller itself does not work, the heating power cannot be applied. If this takes place before discharge, ignition access, of course, cannot be done. If it takes place during the ignition phase, it does not affect it at all, but the normal fusion power shutdown cannot be done because the H-L back transition without heating power accelerates the fusion power decay, and the Borrass density limit becomes lower than the density, leading to the disruption. A similar situation may take place by shutdown pellet injection. Therefore, a control system separated from the feedback system should be installed for the heating power.

In Sec. III.C it has been shown that an overestimated measuring error of $+10 \%$ changes the $\mathrm{H}$ mode to the L mode. In actual ITER experiments, for example, the fusion power will be increased gradually up to $1.5 \mathrm{GW}$ step by step. At the same time, the set value of the $\mathrm{H}$-mode indicator $M_{\mathrm{HL} 0}$ should be chosen as large at 
the first stage to obtain the fusion power in the H-mode regime, even with a subignited operation, and then gradually reduced as the experiments go on. During this initial phase, the diagnostic signals are checked with each other and can be calibrated in-situ relatively rather than absolutely. As each reactor, including ITER, has its own $\mathrm{H}$-mode power threshold and confinement time scaling, the new experimental formula can be established, and all measured parameters are adjusted experimentally during this initial phase. Therefore, the in-situ adjustment of the ignited operation may find the optimum operating point, and the problem requiring high accuracy may be avoided experimentally.

In this study, we have not considered the association of the main plasma core and divertor plasma as treated by the ITER team, ${ }^{40}$ but we have concentrated on the core burn control for simplicity. Upon considering this association, what we should do can be understood from the diagnostic failure point of view. For divertor measurements, the wall temperature measurement of the divertor plate by the ir monitor (ir camera) and radiation measurement by the divertor bolometers should be added. The radiation level can be feedback-controlled to keep the divertor wall temperature less than the critical one. The failure of the ir camera (zero signal) interprets the divertor plate temperature as zero; therefore, no more impurity is injected although more impurities should be injected to keep the divertor plate temperature lower. Thus, many sets of ir cameras must be installed for monitoring the divertor plate temperature in parallel as a backup. A toroidal array of ir cameras may be satisfactory for this purpose.

We have to construct the reliable in-vessel diagnostic systems at first because we may not be able to repair these malfunctional diagnostics frequently after D-T operations. Then the diagnostic network system may serve to compensate the malfunctional diagnostic systems. The intelligent failure and abnormality detection systems must be installed in the diagnostic network system.

\section{SUMMARY}

We have analyzed the consequence of the LOSE of the burn control diagnostic systems and considered failsafe operation in a tokamak reactor.

The failure of neutron measurements for fusion power leads to the fusion power surge for the simple control algorithm of $\left\{P_{E X T}(\mathrm{HL})\right.$ and $\left.S_{\mathrm{DT}}\left(P_{f}\right)\right\}$. However, this fusion power surge may be avoided by switching off the fueling after detecting the diagnostic failure for the simple control algorithm of $\left\{P_{E X T}(\mathrm{HL})\right.$ and $\left.S_{\mathrm{DT}}\left(P_{f}\right)\right\}$, and by the failsafe control algorithm of $\left\{P_{E X T}(\mathrm{HL})\right.$ and $\min \left\{S_{\mathrm{DT}}\left(P_{f}\right)\right.$, $\left.\left.S_{\mathrm{DT}}(n), S_{\mathrm{DT}}(\langle\beta\rangle)\right\}\right\}$ with the interferometer and the diamagnetic loop. A $10 \%$ overestimation of the neutron diagnostics for fusion power $\left(\epsilon_{p n}=+0.1\right)$ leads to ignition termination for the case of $M_{\mathrm{HL} 0}=1.05$ because the ignited operation is conducted near the $\mathrm{H}$-L transition boundary. However, in the initial D-T experimental phase, relative in-site calibration of diagnostics may overcome the calibration problem using the larger set value of the H-mode indicator $M_{\mathrm{HL} 0}$ to ensure fusion power in the $\mathrm{H}$ mode. Failure of the bolometer system $\left(\epsilon_{b}<-0.4\right)$ during the ignition heating phase leads to the ignition termination for $M_{\mathrm{HL} 0}=1.05$. Therefore, its effect is less problematic than that of the neutron diagnostics for fusion power measurement. Interferometry fringe counting error, either jump-up or -down, is not a problem for the machine safety except for the subignited operation. However, $-7 \%$ in interferometer measurements during the heating phase can terminate the ignition for $M_{\mathrm{HL} 0}=1.05$. In subignited operation with $\gamma_{\mathrm{HH}}=0.7$, too much fringe jump-down error may induce disruption after ignition termination, based on the Borrass density limit. Fueling can always be switched off during the normal fusion burn shutdown phase from the safe operating point of view. With this operation, any diagnostic failure cannot lead to an abnormal fusion power surge during the fusion burn shutdown phase. Lost alpha detectors can be removed from the feedback control system for ignition burn by using the presumed set value of $\eta_{\alpha}(\mathrm{set})=$ 0.9 , which provides a wider operation range.

\section{APPENDIX}

\section{ZERO-DIMENSIONAL POWER BALANCE EQUATIONS}

The fueling rate in the plasma $S_{\mathrm{DT}}$ and the external heating power $P_{E X T}$ are used for the core ignition burn control study. The fueling rate assumed here is already deposited in the plasma. Therefore, we are conceiving the compact toroid (CT) injection with the fast plasma response rather than the gas puffing. It is to be noted that as in an actual situation, the CT fueling is repetitive and not continuous; it may provide slightly different simulation results from this study.

The particle balance equation for fuels with the fueling rate $S_{\mathrm{DT}}$ is given by

$$
\frac{d n_{e}(0)}{d t}=\left(1+\alpha_{n}\right) S_{\mathrm{DT}}-\left\{\frac{f_{D}+f_{T}}{\tau_{p}}+\frac{2 f_{\alpha}}{\tau_{\alpha}^{*}}\right\} n_{e}(0),
$$

where

$$
\begin{aligned}
f_{\mathrm{D}} & =n_{\mathrm{D}}(0) / n_{e}(0) \\
f_{\mathrm{T}} & =n_{\mathrm{T}}(0) / n_{e}(0) \\
f_{\alpha} & =n_{\alpha}(0) / n_{e}(0) .
\end{aligned}
$$

The helium ash equation is described by

$$
\frac{d f_{\alpha}}{d t}=\left(1+\alpha_{n}\right) n_{e}(0) f_{\mathrm{D}} f_{\mathrm{T}} \overline{\langle\sigma v\rangle_{\mathrm{DT}}(x)}-\frac{f_{\alpha}}{\tau_{\alpha}^{*}} .
$$


The power balance equation with the external heating power $P_{E X T}$ provides

$$
\begin{aligned}
\frac{d T_{i}(0)}{d t}= & \frac{1+\alpha_{n}+\alpha_{T}}{1.5 e\left(f_{\mathrm{D}}+f_{\mathrm{T}}+1 / \gamma_{i}+f_{\alpha}\right) n_{e}(0)} \\
& \times\left[P_{E X T} / V_{o}+\bar{P}_{\alpha}+\bar{P}_{o h}-\left\{\bar{P}_{L}+\bar{P}_{b}+\bar{P}_{s}\right\}\right] \\
& -\frac{T_{i}(0)}{\left(f_{\mathrm{D}}+f_{\mathrm{T}}+1 / \gamma_{i}+f_{\alpha}\right)} \\
& \times\left[\left(1+\frac{1}{\gamma_{i}}\right) \frac{1}{n_{e}(0)} \frac{d n_{e}(0)}{d t}-\frac{d f_{\alpha}}{d t}\right]
\end{aligned}
$$

The ITER93HP scaling is

$$
\left\{\begin{aligned}
\tau_{\text {ITER93HP }}[\mathrm{s}]= & 0.0532 A_{i}^{0.41} I_{p}^{1.06}[\mathrm{MA}] \bar{n}_{20}^{0.17} \\
& \times\left[\times 10^{20} \mathrm{~m}^{-3}\right] R^{1.9}[\mathrm{~m}] a^{-0.11}[\mathrm{~m}] \\
& \times \kappa^{0.66} B_{t}^{0.32}[\mathrm{~T}] / P_{H T}^{0.67}[\mathrm{MW}] \\
\tau_{A U X}= & \gamma_{\mathrm{HH}} 0.85 \times \tau_{\text {ITER } 93 \mathrm{HP}}
\end{aligned}\right.
$$

The confinement is assumed as $\tau_{E}=\min \left\{\tau_{N A}, \tau_{A U X}\right\}$, where $\tau_{N A}$ is the neo-Alcator scaling.

The various terms and parameters assumed are listed here and in Table A.1. Each term in the power balance equation in Eq. (A.3) is described as follows ${ }^{16}$ :

1. The plasma conduction loss is $\bar{P}_{L}=A_{L} n(0) / \tau_{E}$ with $A_{L}=1.5\left(f_{\mathrm{D}}+f_{\mathrm{T}}+1 / \gamma_{i}+f_{\alpha}\right) T_{i}(0) 1.6 \times 10^{-19} /(1+$ $\left.\alpha_{n}+\alpha_{T}\right)$; the temperature ratio $\gamma_{i}=T_{i}(0) / T_{e}(0) ;$ and the D-T fuel ratio $\gamma_{\mathrm{DT}}=n_{\mathrm{D}}(0) / n_{\mathrm{T}}(0)=f_{\mathrm{D}} / f_{\mathrm{T}}, f_{\mathrm{D}}=$ $\left(1-2 f_{\alpha}-4 f_{\mathrm{Be}}-Z f_{\text {imp }}\right) /\left(1+\gamma_{\mathrm{DT}}\right)$ and $f_{\mathrm{T}}=\gamma_{\mathrm{DT}} f_{\mathrm{D}}$. Here, it is assumed that the plasma energy is given by $W=$ $n_{\mathrm{D}} T_{\mathrm{D}}+n_{\mathrm{T}} T_{\mathrm{T}}+n_{e} T_{e}+n_{\alpha} T_{\alpha}=\left(n_{\mathrm{D}}+n_{\mathrm{T}}+n_{e} T_{e} / T_{i}+\right.$ $\left.n_{\alpha}\right) T_{i}$ with the thermal alpha ash particle having the same temperature as the ion temperature, which is different from the previous analysis. ${ }^{15}$ The mass factor $A_{i}=$ 2.5 was used.

TABLE A.I

ITER-like Plasma Parameters Assumed in This Analysis

\begin{tabular}{|ll|}
\hline Major radius & $R=8.14 \mathrm{~m}$ \\
Minor radius & $a=2.8 \mathrm{~m}$ \\
Toroidal field & $B_{t}=5.68 \mathrm{~T}$ \\
Elongation & $\kappa=1.6$ \\
Plasma current & $I_{p}=21.0 \mathrm{MA}$ \\
Impurity fraction & $n_{\mathrm{Be}} / n_{e}=2 \%$ \\
Alpha-particle confinement time & $\tau_{\alpha}^{*} / \tau_{E}=10$ \\
Temperature ratio & $\gamma_{i}=T_{i} / T_{e}=0.95$ \\
Fuel ratio & $n_{\mathrm{D}} / n_{\mathrm{T}}=1$ \\
Alpha-particle heating efficiency & $\eta_{\alpha}=0.97$ \\
Wall reflectivity & $R_{\text {eff }}=0.9$ \\
Hole fraction & $f_{H}=0.1$ \\
Density profile & $\alpha_{n}=0.15$ \\
Temperature profile & $\alpha_{\mathrm{T}}=0.9$ \\
Enhancement factor & $1.0(\mathrm{ITER} 93 \mathrm{HP})$ \\
Peak electron density & $n(0) \sim 1.21 \times 10^{20} \mathrm{~m}^{-3}$ \\
Peak ion temperature & $T_{i}(0) \sim 23.5 \mathrm{keV}$ \\
Alpha ash fraction & $f_{\alpha} \sim 15.6 \%$ \\
Effective ion charge & $Z_{e f f} \sim 1.55$ \\
Alpha heating power & $P_{\alpha} \sim 286 \mathrm{MW}$ \\
Bremsstrahlung loss & $P_{b} \sim 73 \mathrm{MW}$ \\
Synchrotron radiation loss & $P_{s} \sim 21 \mathrm{MW}$ \\
Plasma conduction loss & $P_{L} \sim 192 \mathrm{MW}$ \\
& \\
\hline
\end{tabular}

2. The alpha heating power is $\bar{P}_{\alpha}=A_{\alpha} n(0)^{2}$, where $A_{\alpha}=f_{\mathrm{D}} f_{\mathrm{T}}\left(3.52 \eta_{\alpha}\right) \overline{\langle\sigma v\rangle}_{\mathrm{DT}} 1.6 \times 10^{-13}, \eta_{\alpha}$ being the alphaheating efficiency.

3. The ohmic heating power is $\bar{P}_{\text {oh }}$, including the neoclassical resistivity.

4. The bremsstrahlung loss is $\bar{P}_{b}=A_{b} n(0)^{2}$, which includes the ion-electron and electron-electron scattering with the relativistic effects. The coefficient $A_{b}$ is given by

$$
\begin{aligned}
A_{b}=1.5 \times 10^{-38} Z_{\text {eff }}\left[\frac{1}{1+2 \alpha_{n}+0.5 \alpha_{T}}+\frac{1}{1+2 \alpha_{n}+1.5 \alpha_{T}} \cdot \frac{2 T_{e}(0)}{m c^{2}}\right] \sqrt{T_{e}(0)} \\
+3 \times 10^{-38}\left[\frac{1}{1+2 \alpha_{n}+1.5 \alpha_{T}}+\frac{0.5}{1+2 \alpha_{n}+2.5 \alpha_{T}} \cdot\left\{\frac{T_{e}(0)}{m c^{2}}\right\}\right. \\
\left.-\frac{3}{1+2 \alpha_{n}+3.5 \alpha_{T}} \cdot\left\{\frac{T_{e}(0)}{m c^{2}}\right\}^{2}\right] \frac{2 T_{e}(0)^{1.5}}{m c^{2}},
\end{aligned}
$$

where $m c^{2}$ is the electron rest energy. Here, $Z_{\text {eff }}=\left(1+\gamma_{\mathrm{DT}}\right) f_{\mathrm{D}}+4 f_{\alpha}+16 f_{\mathrm{Be}}+Z^{2} f_{\text {imp }}, f_{\mathrm{Be}}=n_{\mathrm{Be}}(0) / n_{e}(0), n_{\mathrm{Be}}$ is the beryllium impurity density, and $f_{\text {imp }}=n_{\text {imp }}(0) / n_{e}(0)$, where $n_{\text {imp }}$ is the other impurity density.

5. The synchrotron radiation loss is $\bar{P}_{s}=A_{s} n(0)^{2}$, which includes the relativistic effects, torus effects, and the nonreflecting surfaces such as holes. ${ }^{15,16}$ The coefficient $A_{s}$ is given by 


$$
\begin{aligned}
A_{s}= & 2.5 \times 10^{-56} T_{e}(0)^{4} \gamma_{i}^{1.5} \frac{\left\{f_{\mathrm{D}}+f_{\mathrm{T}}+1 / \gamma_{i}+f_{\alpha}\right\}^{1.5}}{\beta(0)^{1.5} \sqrt{a B_{t}}}\left\{f_{H}+\left(1-f_{H}\right) \sqrt{1-R_{e f f}}\right\} \\
\times & \int_{0}^{1}\left[\left(1-x^{2}\right)^{0.5 \alpha_{n}+2.5 \alpha_{T}\left\{1+T_{e}(0)\left(1-x^{2}\right)^{\alpha_{T}} / 204000\right\}}\right. \\
& \times\left\{1-\beta(0)\left(1-x^{2}\right)^{\alpha_{n}+\alpha_{T}}\right\}^{5 / 4} \sqrt{\left.\sqrt{T_{e}(0)}\left(1-x^{2}\right)^{0.5 \alpha_{T}}+\frac{2 a}{R} \sqrt{\frac{m c^{2}}{2 \pi}}\right] 2 x d x,}
\end{aligned}
$$

where $R_{\text {eff }}$ is the wall reflectivity, $f_{H}$ is the hole fraction, the central toroidal beta is given by $\beta(0)=\langle\beta\rangle\left(1+\alpha_{n}+\right.$ $\left.\alpha_{T}\right)$ with the average toroidal beta $\langle\beta\rangle=\left(f_{\mathrm{D}}+f_{\mathrm{T}}+\right.$ $\left.1 / \gamma_{i}+f_{\alpha}\right) n_{e}(0) T_{i}(0) /\left\{\left(1+\alpha_{n}+\alpha_{T}\right)\left(B_{o}^{2} / 2 \mu_{o}\right)\right\}$.

The electron and ion temperature profiles are assumed to be $T_{i}(x) / T_{i}(0)=T_{e}(x) / T_{e}(0)=\left(1-x^{2}\right)^{\alpha_{T}}$ in this study, respectively.

\section{ACKNOWLEDGMENTS}

One of the authors (O. M.) gratefully thanks I. Yonekawa and Y. Hoshi for encouragement. The authors are grateful to J. Wesley, R. Snider, T. N. Carlstrom, J. B. Lister, V. Mukhovatov, A. Costley, K. M. Young, L. Johnson, P. Stott, S. Kasai, A. Nagashima, T. Nishitani, and T. Sugie for useful discussions and comments at the ITER Diagnostic Expert Meeting at ITER-JWS, San Diego, California, February 11-13, 1998. Comments on the interferometer fringe jump by A. G. Kellman also stimulated this work.

\section{REFERENCES}

1. T. HONDA et al., "Analyses for Passive Plasma Shutdown During Ex-Vessel Loss of Coolant Accident in the First Wall/ Shield Blanket of Fusion Reactor," J. Nucl. Sci. Technol., 34, 6, 538 (1997).

2. T. HONDA et al., "Development of Time Dependent Safety Analysis Code for Plasma Anomaly Events in Fusion Reactors," J. Nucl. Sci. Technol., 34, 3, 229 (1997).

3. N. A. UCKAN et al., "ITER Plasma Safety Interface Models and Assessments," Fusion Technology, p. 1851, C. VARANDAS and F. SERRA, Eds., Elsevier Science, New York (1997).

4. N. MITCHELL et al., "Magnet Safety Assessment for ITER,” J. Fusion Energy, 16, 1/2, 25 (1997).

5. R. CAPORALI and T. PINNA, "Multiple Failure Accident Sequences for SEAFP Reactor," J. Fusion Energy, 16, 1/2, 45 (1997).

6. B. J. MERRILL, L. C. CADWALLADER, and D. A. PETTI, "Safety Analysis Results for Cryostat Ingress Accidents in ITER,” J. Fusion Energy, 16, 1/2, 119 (1997).

7. W. GULDEN et al., "ITER Safety Analyses with ISAS," J. Fusion Energy, 16, 1/2, 75 (1997).
8. L. DI PACE et al., "Analysis of the SEAFP Reactor Fuel Cycle," J. Fusion Energy, 16, 1/2, 55 (1997).

9. H.-W. BARTELS et al., "Fusion Specific Features in ITER Accident Analysis," J. Fusion Energy, 16, 1/2, 3 (1997).

10. A. E. COSTLEY et al., "Requirements for ITER Diagnostics," Diagnostics for Experimental Thermonuclear Fusion Reactors, p. 23, P. E. STOTT, G. GORINI, and E. SINDONI, Eds., Plenum Press, New York (1996) (in Proc. Int. Workshop Diagnostics for ITER, Varenna, Italy, August 28-September 1, 1995).

11. V. S. MUKHOVATOV et al., "Role and Requirements for Plasma Measurements on ITER," Diagnostics for Experimental Thermonuclear Fusion Reactors 2, p. 25, P. E. STOTT, G. GORINI, P. PRANDONI, and E. SINDONI, Eds., Plenum Press, New York (1998) (in Proc. Int. Workshop Diagnostics for ITER, Varenna, Italy, September 4-12, 1997).

12. A. E. COSTLEY et al., "Overview of the ITER Diagnostic System," Diagnostics for Experimental Thermonuclear Fusion Reactors 2, p. 41, P. E. STOTT, G. GORINI, P. PRANDONI, and E. SINDONI, Eds., Plenum Press, New York (1998) (in Proc. Int. Workshop Diagnostics for ITER, Varenna, Italy, September 4-12, 1997).

13. O. MITARAI and K. MURAOKA, "Consideration on Control and Diagnostic for ITER-EDA," presented at 2nd ITER Expert Mtg. on Diagnostics, Naka, Japan, February 8-9, 1995.

14. O. MITARAI and K. MURAOKA, "Scenarios for Diagnostics and Control on ITER," presented at 4th ITER Expert Mtg. on Diagnostics, Moscow, Russia, March 1-2, 1996.

15. O. MITARAI and K. MURAOKA, Plasma Physics and Controlled Fusion, Vol. 36, p. 551 (1996).

16. O. MITARAI and K. MURAOKA, "Ignition Analyses for Burn Control and Diagnostic Developments in ITER," Nucl. Fusion, 37, 1523 (1997).

17. O. MITARAI and K. MURAOKA, "Ignition Analyses with ITER89P and ITER93HP Scalings for Burn Control and Diagnostics in ITER-ID," Plasma Physics and Controlled Fusion, Vol. 40, p. 1349 (1998).

18. ITER Technical Advisory Committee, Report of TAC-12 Mtg., Garching Joint Work Site, Germany, June 30-July 2, 1997.

19. O. MITARAI and K. MURAOKA, "Ignition Burn Control and Diagnostics in ITER," Diagnostics for International Thermonuclear Experimental Reactor, p. 93, Plenum Press, New 
York (Dec. 1998) (Int. Summer School of Plasma Physics, Varenna, Italy, September 4-12, 1997).

20. O. MITARAI and K. MURAOKA, "A Proposed Set of Diagnostics for Core Ignition Burn Control in a Tokamak Reactor," Nucl. Fusion (June 1999).

21. A. W. EDWARD et al., "The Use of X-Ray Diagnostics in Plasma Control," Diagnostics for Experimental Thermonuclear Fusion Reactors 2, p. 573, P. E. STOTT, G. GORINI, P. PRANDONI, and E. SINDONI, Eds., Plenum Press, New York (1998) (in Proc. Int. Workshop Diagnostics for ITER, Varenna, Italy, September 4-12, 1997).

22. D. BOUCHER and J. WESLEY, "Modeling of ITER Operation," Proc. 21 st EPS Conf. Plasma Physics and Controlled Fusion, Montpellier, France, June 27-July 1, 1994, Vol. 18B, Part 2, p. 525 (1994).

23. D. BOUCHER et. al., "ITER Fusion Performance Projections," Proc. 24th EPS Conf. Plasma Physics and Controlled Fusion, Berchtesgarden, Germany, June 9-13, 1997, Vol. 21A, Part III, p. 953 (1997).

24. D. BOUCHER et al., "ITER Scenarios Including NonInductive Steady State Operation," Proc. 16th IAEA Fusion Energy Conf., Montréal, Canada, October 7-11, 1996, Vol. 2, p. 945, International Atomic Energy Agency (1997).

25. "ITER Plasma Performance and Operations," ITER Detailed Design Report, Chap. III, Sec. 6.0, International Thermonuclear Experimental Reactor (Dec. 1996).

26. J. WESLEY et al., "Plasma Control Requirements and Concepts for ITER,” Fusion Technol., 32, 495 (1997).

27. T. HONDA et al., "Transient Behaviors of Plasma and InVessel Components When Considering Divertor Plasma State Transition in a Fusion Reactor," J. Nucl. Sci. Technol., 35, 12, 916 (1998).

28. T. TAKIZUKA et al., "Threshold Power and Energy Confinement for ITER," Proc. 16th Fusion Energy Conf., Montréal, Canada, October 7-11, 1996, IAEA-CN-64/F-5, Vol. 2, p. 795, International Atomic Energy Agency.
29. M. GREENWALD et al., Nucl. Fusion, 28, 2199 (1988).

30. "Diamagnetic Loop," ITER Design Description Documents DDD, WBS 5.5.A.05, International Thermonuclear Experimental Reactor (1997).

31. K. BORRASS et al., Nucl. Fusion, 33, 63 (1993).

32. R. T. SNIDER "Application of Interferometry and Faraday Rotation Techniques for Density Measurements on the Next Generation of Tokamaks," Rev. Sci. Instrum., 68, 1, 728 (1997).

33. Y. KAWANO and A. NAGASHIMA, "Two-Color Polarimeter for Electron Density Measurement on Large Tokamaks," Rev. Sci. Instrum., 68, 11, 4035 (1997).

\section{V. MUKHOVATOV, Personal Communication.}

35. F. E. CESIL et al., "Development of Thin-Foil Faraday Collector Array as a Lost Alpha Particle Diagnostic for High Yield $d$ - $t$ Fusion Plasmas," Diagnostics for Experimental Thermonuclear Fusion Reactors 2, p. 525, P. E. STOTT, G. GORINI, P. PRANDONI, and E. SINDONI, Eds., Plenum Press, New York (1998) (in Proc. Int. Workshop Diagnostics for ITER, Varenna, Italy, September 4-12, 1997).

36. "Microfission Chambers," ITER Design Description Documents DDD, WBS 5.5.B.03, International Thermonuclear Experimental Reactor (1997).

37. T. NISHITANI et al., "Neutron Monitor Using Micro Fission Chambers for ITER," Rev. Sci. Instrum., 70, 1, Part II, 1141 (1999).

38. "Radial Neutron Camera," ITER Design Description Documents DDD, WBS 5.5.B.01 (1997).

39. "Neutron Flux Monitor," ITER Design Description Documents DDD, WBS 5.5.B.04 (1997).

40. G. VAYAKIS et al., "Plasma Diagnostics in ITER Control," Proc. 25th EPS Conf. Plasma Physics and Controlled Fusion, Prague, Czech Republic, June 29-July 3, 1998, Vol. 22C p. 1594 (1998).

Katsunori Muraoka (DEng, Kyushu University, Japan, 1970) is a professor at Kyushu University in the Department of Applied Science for Electronics and Materials. His work is concerned with development of laser-aided plasma diagnostics and understanding of plasma states using developed techniques.

Osamu Mitarai (DEng, Kyushu University, Japan, 1979) is a professor at Kyushu Tokai University in the School of Engineering, Department of Electrical Engineering. He is currently interested in the integration of diagnostics and the fusion burn control system in a reactor, including the International Thermonuclear Experimental Reactor (ITER), plasma current startup in a spherical tokamak reactor, the advanced $\mathrm{D}-{ }^{3} \mathrm{He}$ tokamak reactor, and AC tokamak operations. 